\title{
RECIPROCIDADES, INTERCAMBIO Y JERARQUÍA EN LAS COMUNIDADES MEDIEVALES
}

por

\author{
ANA RODRíguEZ LÓPEZ \\ REYNA PASTOR \\ Instituto de Historia. C.S.I.C.
}

RESUMEN: Reciprocidad, don/contradon, ban sido conceptos utilizados por los medievalistas desde bace decadas. Pero las propias formulaciones de los bistoriadores ban generado nuevos problemas de tipo cronologico-evolutivo $y$ de organizacion social. En este artículo se estudian las relaciones sociales de un monasterio cisterciense a través de sus intercambios con las grupos dominantes locales $y$ con las comunidades campesinas de $\mathbf{s u}$ entormo en los siglos XII y XIII. A través de él, las autoras argumentan que la reciprocidad puede ser un instrumento de análisis válido para explicar cómo se definen nuevas posiciones sociales, cómo se establecen jerarquias y cómo se produce movilidad y diferenciación social en el momento en que se organizan los sistemas de poder.

Palabras Clave: Edad Media. Reciprocidades. Intercambio desigual. Movilidad y diferenciación social. Galicia. Instituciones eclesiásticas. Comunidades locales.

ABSTRACT: Recipracity, gift and counter gift are concepts wbich bave been widely used by medievalists in the last decades. However, these concepts bave generated new problems negarding their chronology, evolution and social meaning. This anticle analyses the social relations of a Cistercian monastery through its exchanges with the local dominant groups and the peasant communities of its binterland in the 12 th and 13 th centuries. The authors argue that reciprocity can be a valid means of analysis for the explanation of bow new social positions are defined, how bierartbies are establisbed and bow social movility and differentiation arize when systems of ponver are organized.

KEY wORDS: Middle Ages. Reciprocity. Unequal exchange. Social movility and differenciation. Galicia. Monastic institutions. Local communities. 
«Por toda la sociedad entera corrían los canales, continuamente diversificados, de una circulación de riquezas y de servicios suscitada por las generosidades necesarias. Las de los dependientes hacia sus patronos, las de los padres hacia la desposada, las de los amigos hacia el organizador de una fiesta, las del rey hacia los grandes, las de todos los ricos hacia todos los pobres, y finalmente, las de todos los hombres para con los muertos y para con Dios. Se trata de intercambios - y son innumerables- pero no se trata de comercion. Georges Duby, Guerreros y Campesinos. Desarrollo inicial de la economía europea (500-1200), Madrid, 1976, pág. 71 (1ª ed. francés, 1973).

En su obra clásica de 1973, Guerreros y Campesinos. Desarrollo inicial de la economía europea (500-1200), Georges Duby señalaba que una parte considerable de la producción medieval se hallaba incluida en una amplia circulación de generosidades necesarias, y añadía que gran número de los censos y prestaciones que los campesinos estaban obligados a hacer a sus señores recibieron durante mucho tiempo en el lenguaje corriente el nombre de regalos, eulogiae . Esta observación venía precedida de una referencia al Ensayo sobre el don de Marcel Mauss: «En las economías anteriores a las nuestra no se hallan prácticamente nunca simples intercambios de bienes, de riquezas y de productos en el curso de un mercado entre individuos. Ante todo, no son los individuos sino las colectividades las que se obligan mutuamente, intercambian y contratan [...] y en segundo lugar lo que estas comunidades cambian no son exclusivamente bienes y riquezas muebles y raíces, cosas útiles económicamente [...]. Finalmente, estas prestaciones y contraprestaciones se completan con presentes y regalos, formalmente voluntarios, aunque en el fondo sean rigurosamente obligatorios bajo pena de guerra privada o pública». Frente a un mercado entre individuos se acentuaba, y así lo recogía Duby, el intercambio entre colectividades como un factor de producción y reproducción social.

Esta deuda con la teoría antropológica, sin embargo, no era la primera vez que se expresaba abiertamente en el medievalismo. En las décadas previas a la obra de Duby se había desarrollado la reflexión sobre el don a través de préstamos procedentes de la etnología en un intento de explicar diversos fenómenos medievales, de los que nos interesa destacar dos. El primero de ellos, la desaparición del comercio en la Alta Edad Media, tal y cómo había sido planteada en el marco del debate sobre las teorías de Pirenne, y el segundo, la «irracionalidad» de la mentalidad y los modos de vida de la nobleza medieval.

1 DuBY, G.: Guerreros y Campesinos, Desarrollo inicial de la economia europea (500-1200), Madrid, 1976, p. 64 (1 $1^{\text {a }}$ ed. francesa 1973). Eulogia se define, entre otros sentidos, como un don ofrecido en prueba de amistad o de honor. Pero tiene además otras acepciones relacionadas con un carácter obligatorio: un don ofrecido por un eclesiástico a su obispo en signo de honor, un don más o menos obligatorio ofrecido por los creyentes al obispo o al arcediano con ocasión de un sínodo, o un don obligatorio presentado por los justiciables al señor como reconocimiento. Estas son las acepciones que recoge NiermeYer, J.F.: en su Mediae Latinitatis Lexicon Minss, Leiden, 1976. 
La comparación con otras sociedades proporcionaba así herramientas para desentrañar la lógica de los intercambios en el mundo medieval, tanto los que se situaban al margen de relaciones puramente comerciales como los que se jugaban en el campo de la competición por el honor y el prestigio.

La discusión de las tesis del historiador belga Henri Pirenne sobre el cometcio en la Alta Edad Media y las críticas que suscitaron abrieron el debate sobre las diferentes formas de intercambio desarrolladas a lo largo de esos siglos. Llamando la atención sobre la importancia de las donaciones y de los robos como formas fundamentales de transferencia de propiedades en la época altomedieval, el numísmata británico Philip Grierson afirmaba que la distorsión del debate sobre las tesis pirennianas venía dada por el hecho de pensar que los bienes pasaban de unas manos a otras necesariamente a través del comercio e insistía -frente a esto- en esos canales que definiría luego Duby, los que colocaban a los unos moralmente en deuda con los otros, los que permitían la circulación de bienes y servicios sin pasar por las vías del comercio monetarizado ${ }^{2}$.

Abordando el complejo problema del desarrollo de las relaciones de propiedad en la Alta Edad Media, el historiador ruso Aaron Gurevic mostraba que algunas nociones aparentemente limitadas a este campo se inscribían en un sistema conceptual más amplio, al que necesariamente había que incorporar las relaciones en el seno de la colectividad familiar y patrimonial y la representación de los vínculos entre el hombre y la naturaleza. La inexistencia de límites precisos entre las personas y las cosas, entre los objetos y sus propietarios constituían una característica esencial del mundo feudal y de sus específicas relaciones de propiedad ${ }^{3}$.

A través del análisis de fuentes escandinavas, Gurevic llegaba a la conclusión de que el sistema de intercambio de la temprana Edad Media no se basaba ni en el valor material de los objetos que pasaban de unas manos a otras ni en su valor de uso. Por el contrario, lo que se situaba en primer plano era el procedimiento mismo del intercambio ya que el don generaba un vínculo especial

2 GrIERson, Ph.: «Commerce in the Dark Ages. A critic of evidence», Transactions of the Royal Historical Saciety, $5^{a}$ serie, 9 (1959), pp. 123-140 y aLa fonction sociale de la monnaie en Angleterre aux VII-VIIIe siècles", Moneta e scambi nell'Alto Medioevo. Settimane di Studio del Centro Italiano di Studi sull'Alto Medioevo, Spoleto, 1961, pp. 341-362. Comentando a Grierson en relación con el tráfico de reliquias en la Alta Edad Media, Patrick Geary añade que incluso cuando una compra subyacía en el corazón de los intercambios, los contemporáneos entendían estas transacciones dentro del contexto de formas más significativas de circulación de bienes, como la donación o - en el caso de las reliquias - ef robo. GEARY, P.: «uSacred commodities: the circulation of medieval relics", en APPADURAI, A.: The Social Life of Things. Commodities in cultural perspectities, Cambridge, 1986, pp. 169-191.

3 GUREvic, Aaron: «Répresentations et attitudes à l'égard de la propiécé pendant l'Haut Moyen Âge", Annales (E.S.C.), 27, 3 (1972), p9. 523-547. El desarrollo de estos planteamientos se amplia a otros aspeccos de la sociedad medieval en la obra del mismo auzor Les catégories de la culture médiévale, Paris, 1983 (edición en ruso, 1972). Significativamente, la edición francesa iba precedida de un prólogo de Georges Duby. 
entre el donante y el receptor ${ }^{4}$. El sentido social de la riqueza estaba alejado del dominio exclusivo de la economía y se ampliaba al de la religión, la ética y la conducta del hombre. La riqueza en el mundo feudal no era un fin en sí mismo, era el arma que permitía afirmar el honor, era un símbolo del poder político y un medio de sustentar ese poder. En este contexto, la generosidad era un atributo necesario al señor, una generosidad agresiva en un juego cuyo objetivo era el prestigio social, sentido que recordaba a Gurevic las prácticas de potlacb desarrolladas en otras sociedades. En realidad, la comparación entre la prodigalidad de la nobleza feudal y la destrucción ritual de bienes en las ceremonias del potlach de los indios de la costa noroeste de América tal como fueron descritas por los antropólogos clásicos había sido establecida por Marc Bloch en la década de 1930. Escribía en La Sociedad Feudal: «Un cronista nos ha transmitido el recuerdo de la singular competición de despilfarro de la que fue teatro un día una reunión cortesana en la región de Limoges. Un caballero hizo sembrar de monedas de plata un terreno, anteriormente labrado; otro, para su cocina, hacía quemar cirios; un tercero, por jactancia, ordenó quemar vivos treinta de sus caballos. ¿Qué hubiera pensado un mercader de esta justa de prestigio, que evoca a nuestra memoria ciertos relatos de los etnógrafos?»s.

Nuevos aspectos se iban perfilando en los análisis de las formas de intercambio y de los modos de vida de las clases dominantes en el mundo medieval a la luz de interpretaciones holistas y de comparaciones amplias. A partir de estas obras - y no sólo de ellas- conceptos como don, contradon, reciprocidad se encuentran cada vez con más frecuencia en las investigaciones de los medievalistas. Pero el análisis histórico de las formas de intercambio en las comunidades medievales revela contradicciones implícitas en la forma en la que se ha producido la transposición de conceptos entre disciplinas, teniendo además en cuenta la ambigüedad de algunos de ellos desde su formulación ${ }^{6}$. EI préstamo conceptual estaba en cierto sentido viciado desde sus orígenes al producirse una curiosa paradoja: algunas de las aproximaciones más valiosas que habían abierto el camino a nuevas formas de ver y de comprender la sociedad

4 Según Gurevic, la creencia de que no existe límite preciso entre el objeto y su propietario estaba en la base de buena parte de las representaciones de la riqueza en la Alta Edad Media. Estas creencias, fundamentales para comprender el derecho de propiedad altomedieval, pervivieron de forma residual en épocas posteriores, como se percibe en el culto de la espada en la caballería o la veneración de objetos sagrados en el cristianismo medieval. Añadimos, evidentemente, las reliquias como los principales «objetos» sagrados. Ver GEARY, P.: «Sacred commodities..».

s Vol. II, p. 35 (edición española, Madrid, 1979). En términos y fechas similares se manifestaba HuIZINGA, Johan: Honzo Ludens. El juego como elemento de la bistoria, Lisboa 1943 (original, Leiden, 1938).

$6 \mathrm{Y}$ los interminables debates que han generado. Como muestra, las discusiones entre historiadores y antropólogos en torno a los problemas de la noción de reciprocidad cal como fue formulada por K. Polanyi en el Dossier titulado Pour une bistoire anthropologique: la notion de réciprocité, en Annales (E.S.C.), 89, 6 (1974).

Hispania, LX/1, núm. 204 (2000) 63-101 
medieval conducían, en última instancia, a otros problemas para cuya resolución eran inútiles, precisamente, esos nuevos instrumentos de análisis.

Si revisamos las interpretaciones citadas más arriba vemos este tipo de problemas. En primer lugar, la reciprocidad o las formas económicas de don/contradon así explicadas se corresponden exclusivamente con un momento en la evolución de los sistemas sociales hacia las relaciones de mercado, una etapa primitiva correspondiente a los siglos altomedievales y a los comportamientos económicos de los pueblos germánicos que sería superada con la reorganización de los circuitos comerciales. La introducción del derecho romano, señala Gurevic, fue acompañada de una extensión de la noción de propiedad privada que llevó aparejada una nueva actitud ante el trabajo y la propiedad. Como consecuencia de todo ello, la clase dominante se fue adaptando a nuevas situaciones económicas, al desarrollo del comercio y al valor de la propiedad tertitorial y de la riqueza. Aunque no se explicita en estos términos, se vinculaba reciprocidad, propiedad colectiva y difusa y formas fuertemente personalizadas de relaciones frente a comercio, propiedad privada y -en última instancia- racionalidad económica ${ }^{7}$.

En segundo lugar, y en estrecha relación con lo anterior, la economía del don en su vertiente de generosidad necesaria quedaría -en el marco de este proceso de desarrollo- - irremediablemente confinada a un horizonte cultural en el que se movían casi exclusivamente los grupos dominantes de la sociedad ${ }^{8}$. Quedaría fosilizada en los modos de vida de la nobleza como una forma de mantener el estatus social o, en las comunidades campesinas, como vestigios de igualitarismo reflejados en las diferentes solidaridades que ligaban a sus miem-

\footnotetext{
7 Esta idea evolutiva está en el fondo presente en la mayor parte de la historiografia medieval. Un ejemplo entre muchos otros: LITTLE, L.K.: Religious Poverty and the Profit Economy in Medieval Europe, Londres, 1978. Contrapone la economía del don a la economía de mercado y a las nuevas formas económicas que van surgiendo en el siglo XI. El capítulo en el que todo esto se trata tiene un título significativo: «From gift economy to profic economy». Gurevic concluye, no obstante, que a pesar de la similicud entre el intercambio de dones y servicios en la Edad Media y el intercambio ritual en otros pueblos, estas formas de relación eran diferentes. Insiste, de hecho, en que ninguna institución social, política o económica, incluída la riqueza, puede comprenderse al margen de los sistemas de valores y el contexto cultural de sociedades concretas. Ver infra la forma en que Gurevic enlaza los presupuestos de la economía substantiva y los del materialismo.

B La prodigalidad como virtud nobiliaria era un topos recurrente en la poesía trovadoresca. Son bien conocidos ejemplos de la literatura del siglo XII. Pierre Cardinal es un ejemplo: Ges non dic mal ad armas ni a sen, / Mas donar sobre totz senboria (No hablo mal de las armas ni de la razón, pero los regalos lo gobiernan todo). La proximidad de las nociones de «dar» y de «tomar" en la lengua de los trovadores recuerda un similar recorrido en las lenguas indoeuropeas según los trabajos clásicos de Emile Benveniste. A este respecto, ver BENVENISTE, E.: «Gift and exchange in the Indo-European Vocabulary", en SCHRIFT, A.D.: The Logic of the Gifi. Toward an Etbic of Generosity, Londres, 1997, pp. 33-44 (artículo en francés de 1948-9). La raíz indoeuropea do puede significar «dar» o atomar» dependiendo de la construcción gramatical, lo que ilustra sobre la ambivalencia de los términos relativos al intercambio.
} 
bros. En suma, dos niveles sin conexión alguna entre ellos, dos circuitos de reciprocidad completamente autónomos: los nobles compitiendo en prodigalidad entre nobles, los campesinos solidarizándose con otros campesinos ${ }^{9}$.

Y es, sin embargo, en la conjunción entre estos dos niveles, en el análisis de las múltiples reciprocidades que ligan a los grupos dominantes con las comunidades locales, donde podemos encontrar algunos rasgos explicativos de la dinámica social del período. Los intercambios entre estos dos niveles diferenciados incluyen y generan movilidad y diferenciación social, la reciprocidad desigual organiza las relaciones horizontales entre grupos sociales, pero también las jerárquicas y verticales en la formación de las dependencias entre nuevos señores y comunidades ya establecidas. Estos son los planteamientos que proponemos - aceptando y discutiendo también la pertinencia de diversas aproximaciones de historiadores y antropólogos - en el marco de un minucioso análisis histórico que realizamos a continuación. Se desvela, así, una sociedad diferenciada, compleja y múltiple en la cual la reciprocidad no es un mecanismo regulatorio que mantiene a los distintos grupos social y políticamente estables, sino una construcción disputada de poder que se teviste de formas y significados diferentes según las situaciones históricas a las que responde.

Nos hemos centrado para ello en el estudio de los intercambios que para los siglos XII y XIII se recogen en el cartulario de una institución eclesiástica, el monasterio cisterciense gallego de Santa María de Oseira. Las dos partes que componen esta investigación exploran las relaciones entre el cenobio y los dos grupos fundamentales - si bien las fronteras entre uno y otro en ocasiones no son fáciles de fijar- con los que intercambia y que aparecen representados en la documentación. En primer lugar, los grupos dominantes locales, muy heterogéneos y en ocasiones preexistentes en la zona. En segundo lugar, las comunidades campesinas de su entorno, vinculadas desde poco después de su fundación al monasterio y generalmente despojadas de sus tierras en los momentos iniciales de la presencia de este nuevo poder. Se trata de desentrañar, en un mundo en el que el poder está fragmentado y los recursos materiales e inmateriales disponibles necesarios para su reproducción se encuentran muy repartidos, cómo se transforman los marcos sociales a través de reciprocidades desiguales, cómo se generan orden y conflicto en una sociedad local.

9 Todo ello sin contar con otros problemas derivados de las interpretaciones de términos y conceptos. Por ejernplo, aunque pueda afirmarse que en general -y no sólo en la sociedad medieval- aristocracia es sinónimo de generosidad, ello no significa necesariamente que se entre en una competencia del tipo del potlach, si por tal fenómeno se entiende - y así debe entenderse, según $\mathrm{M}$. Godelier - un acto que permite adquirir un título o rango, no sólo mantenerlo: un proceso competitivo, agonístico, que se caracteriza por donas con la intención de romper la reciprocidad de los dones, un proceso de ruptura de los equilibrios opuesto en esencia al mantenimiento de un estatus que parece estar detrás del despilfarco de la nobleza feudal. GoDeller, M.: El enigma del don, Barcelona, 1998 ( $1^{\text {a }}$ edición francesa París, 1996), p. 226.

Hispania, LX/1, núm. 204 (2000) 63-101 


\section{RECIPROCIDADES DESIGUALES EN EL INTERIOR DE LOS GRUPOS DOMINANTES}

Las relaciones que vincularon a los monasterios que se implantaron en el territorio gallego en las décadas centrales del siglo XII con los grupos dominantes locales, se basaron en un complejo sistema de negociación que contemplaba la redefinición constante de sus posiciones y que terminó mostrando la dificultad de los nuevos señores para hacerse con los cauces de poder en la sociedad local. Una sociedad local que había ido configurando una clase variada de poder - grupos emparentados con una estructura familiar amplia pero laxa, grupos de parentesco proclives a la alianza durante el cicio vital de los adultos pero abocados a la dispersión patrimonial por la herencia, entremezclados con comunidades de beredes aunque destacados con respecto a éstas- sobre cuya organización y recursos previos a la fundación monástica poco podemos aventurar. Esta clase variada de poder protagoniza buena parte de los intercambios que se registraron en el curso de estos siglos en el cartulario del monasterio cisterciense de Oseira ${ }^{10}$.

10 El monasterio de Santa Maria de Oseira (situado en el municipio actual de San Cristobo de Cea) es el más septencrional de los cenobios orensanos, cercano a la convergencia de límites de tres provincias gallegas, Ourense, Lugo y Pontevedra. Las propiedades que formaban su dominio se repartían en las tres provincias indicadas en un radio de unos $25 \mathrm{Km}$. en torno al monasterio; a ellos se añadían algunos bienes situados en Marín en la costa pontevedresa y otros de menor significación. El monasterio comenzó su andadura en el an̄o 1137, cuando se produjo la donación y acotamienro del lugar por el rey Alfonso VII. La fecha de su adscripción al Cister es muy discutida por los especialistas, que la sitúan entre 1148 y 1199. Los reyes de Castilla y León desde Alfonso VII y los monarcas leoneses Fernando II y Alfonso IX dotaron al monasterio de bienes importantes al tiempo que lo fueron eximiendo de cargas, como el portazgo, y ampliaron su coto. Su etapa fundacional se cerró en los años finales del siglo XII, cuando terminó la concesión de privilegios regios. A fines de este siglo y comienzos del XIII, se inició una política de compras y de expansión propia, así como la explotación de sus bienes de forma indirecta, especialmente mediante contratos de foro. El impulso expansivo del monasterio se debilitó en los últimos dos decenios del siglo XHIl. La evolución del dominio monástico se estudia minuciosamente en ROMANí MARTíNEZ, M.: El manasterio de Santa María de Oseira (Ourense). Evtudio bistórico (1137-1310), Santiago de Compostela, 1989, y su documentación ha sido publicada en Romaní MARTínez, M.: Colección diplomática del monasterio cisterciense de Santa María de Oseira (Ourense). 1025-1310, 2 vols. Santiago de Compostela, 1989, y Romaní, M., PoRtela, M.J., Rodríguez, M.P., VázQuez, M.: Colección diplomática del monasterio cisterciense de Santa Maria de Oseira (Ourense). 1310-1399, Santiago de Compostela, 1993. El análisis de las relaciones sociales en la zona ha sido realizado en otros trabajos. Ver PASTOR, R y RODRÍGUEZ López, A.: «Compraventa de tierras en Galicia. Microanálisis de la documentación del Monasterio de Oseiran, Hispania, 191 (1996), pp. 953-1024, y PASTOR, R., PASCUA ECHEGARAY, E., RODRÍGUEZ LÓPEZ, A. y SÁNCHEZ LEON, P.: Transacciones sin mercado: instituciones, propiedad y redes saciales en la Galicia monástica. 1200-1300, Madrid, 1999. El número total de donaciones recogidas en el cartulario del monasterio de Oseira desde su fundación hasta el final del siglo XIII se situa en torno a las 250 , los foros en torno a los 200 , mientras que las compraventas son mucho más numerosas, en torno a las 650. 
Ante la profunda transformación que se operó en la zona con la llegada de los monjes cistercienses de la mano de la monarquía castellano-leonesa ¿Cómo se transformaron los equilibrios entre los diferentes grupos que controlaban poder y recursos económicos y cómo se generaron nuevas jerarquías entre ellos? ¿Cuáles fueron las formas que adoptaron estos intercambios? ¿Sobre qué tipo de bienes se fundó la estrategia de la reciprocidad, las generosidades necesarias, entre el monasterio y los poderosos locales?

O, para decirlo de otra manera: ¿Por qué - y mediante qué mecanismosestos grupos se vieron abocados a entrar en un ciclo de reciprocidad, en una interminable sucesión de compromisos que se formalizaron en el establecimiento de derechos y deberes, de obligaciones que generaban beneficios que a su vez encadenaban nuevas obligaciones?

A primera vista, parece tratarse de un intercambio equilibrado, horizontal, entre grupos privilegiados en la sociedad que se repartían el poder y que, en todo caso, competían entre sí por el control de las comunidades campesinas, de sus tierras y de sus rentas. Estas relaciones entre iguales - que canalizaban procedimientos de distribución de bienes en la clase dominante-- les habtían permitido ir extendiendo con el tiempo sus redes de amigos, aliados y vasallos. Pero la realidad es que no eran relaciones entre iguales. Las situaciones en el interior de los grupos laicos establecidos en la zona no eran homogéneas, entremezclándose desde linajes de la alta nobleza con implantación supralocal que desempeñaban funciones políticas delegadas por los monarcas - merinos, por ejemplo- hasta grupos familiares menores dependientes que se encontraban inmersos en procesos de disgregación patrimonial $u$ otros que se fueron consolidando al abrigo de las nuevas redes monásticas. Estas distintas situaciones incidían en su capacidad de exigir reciprocidad a los monasterios.

Los intercambios en el interior de esta clase dominante, laica y eclesiástica no generaron igualdades ni simetrías, no fueron un factor de equilibrio entre los intereses de unos y de otros. Crearon, por el contrario, nuevas desigualdades y jerarquías, en un proceso cuyo resultado fue la transformación de estos grupos, la consolidación de unos, el debilitamiento de otros, la aproximación a los señores eclesiásticos de la zona o su alejamiento definitivo. Eran intercambios que incluían y generaban diferenciación y movilidad social.

La reciprocidad definía nuevas posiciones. No expresaba cambios paritarios, sino que revelaba que la norma era la desviación del cambio equilibrado y que, sólo teniendo en cuenta esta desviación se podía entender cómo interactuaban la reciprocidad, las relaciones sociales y las circunstancias materiales ${ }^{11}$. Su po-

11 "En realidad, es precisamente mediante el escrutinio de los momentos en que se aparta de un intercambio equilibrado la forma en que podemos entrever la interacción entre la reciprocidad, las relaciones sociales y las circunstancias materiales». SAHLINS, M.: Economia de la Edad de Piedra, Madrid, 1977 ( $1^{a} \mathrm{ed}$. inglés 1974), p. 209; LEVI, G.: La berencia inmaterial. La bistoria de un exorcista piamontés del siglo XVI, Madrid, 1990, al hacer referencia a que el uso del concepro de reciprocidad le permite tomar en consideración las transacciones en el mercado de la tierra como si fueran no 
tencialidad era, en última instancia, su capacidad de individualizar y diferenciar en el interior de las comunidades locales.

Un recorrido minucioso por la abundante documentación del monasterio de Oseira a lo largo de los siglos XII y XIII nos permite llevar a cabo un análisis preciso de las transacciones - que definen un proceso económico inserto en un conjunto más amplio de relaciones sociales- entre los miembros de la institución monástica y los que en otro trabajo hemos definido como grupos intermedios altos. En líneas generales, se trata de un numetoso conjunto de grupos familiares que ejercían un poder local, que poseían tierra pero que habitualmente no la trabajaban y que formaban parte de las redes sociales y políticas de la nobleza, a la que se encontraban ligados por vínculos de fidelidad y vasallaje $\mathrm{e}^{12}$.

\section{El vínculo social del intercambio}

Desde la implantación cisterciense en Oseira, la relación entre el monasterio y los grupos poderosos locales estuvo marcada por abundantes y complejos intercambios de bienes y de servicios. ¿Cuáles fueron los vinculos sociales que las transacciones crearon entre las partes? ¿Qué obtenía cada una de ellas en el curso de estos intercambios? ¿Existía, en fin, equilibrio entre la acción de dar y la devolución de lo dado?

La estrategia temporal marcó desde su origen las transacciones entre estos laicos y los monjes de Oseira. El monasterio -así como las demás instituciones eclesiásticas medievales- tenía de partida una ventaja organizativa, ya que debía su fuerza a la continuidad que representaba como institución, una conti-

siempre cambios paritarios y expresión de equilibrio entre iguales. Afirma que, de hecho, la reciprocidad que actua en el mercado de la sierra revela, por el contrario, que la desviación de un cambio equilibrado es la norma.

12 Los criterios para la definición de estos grupos intermedios se han establecido en RoDRiGUEZ LÓPEZ, A.: «Estrategias monásticas y relación con los grupos dominantes locales. La influencia del monasterio de Oseita en el medio social en el siglo XIII", en Transacciones sin mercado..., pp. 139192. Con respecto a los grupos intermedios/altos a los que se dedica este análisis, los criterios se referían a la calificación social (dominus, domina), al ejercicio de funciones de tipo político (caballeros o milites, escuderos o armigeri), si bien en su mayotía eran grupos que generalmente carecían de signos exteriores que denotaran una cierta preeminecia social pero cuyas redes de relaciones minuciosamente deducidas hacían ver que se trataba de gente importante que podía negociar con el monasterio, ejercer presión sobre él o limitar su capacidad de maniobra. Por otra parte, la capacidad de inserción de los cistercienses en la sociedad local ha sido destacada en la bibliografia, que ha hecho especial hincapié en su habilidad para relacionarse y establecer vínculos con los grupos dominantes a escala local, con los militer en particular. Cf. BERMAN, C.H.: Medieval Agriculture, the Southerm French Countryside, and the Early Cistercians. A study of Fonty-three Monasteries, Transactions of the American Philosophical Society, vol. 76, part 5, 1986, BoUCHARD, C.B.: Cistercians, Knights, and Economic Exchange in Twelfib Century Burgundy, Ithaca-Londres, 1991.

Hispania, LX/1, núm. 204 (2000) 63-101 
nuidad que lo capacitaba para una negociación a largo plazo. La crganización en linajes laicos y comunidades eclesiásticas en la Edad Media - como ha puesto de relieve P. Sánchez Léon- respondía no sólo a una división funcional, como tiende a aceptarse comúnmente, sino sobre todo a trayectorias políticoinstitucionales de larga duración que condicionaban las normas de comportamiento de sus respectivos miembros en cuestiones económicas y sociales esenciales $^{13}$.

Se trata éste de un aspecto fundamental. Un minucioso análisis documental hace ver que el monasterio de Oseira transformó en el tiempo - mediante procesos de intercambio con los poderosos locales y a través de un papel mediador evidente en la mayor parte de la documentación - los marcos previos de las relaciones personales. ¿Cómo se produjo esta transformación? La acción del tiempo marcó claramente las diferencias, aunque todos los que participaban en estos procesos se beneficiaron, aparentemente, de las relaciones anudadas.

Los propietarios locales donaban tierra. El contradon monástico era de otra naturaleza. En esencia, el monasterio ofrecía certidumbre a los intereses de estos pequeños nobles y grupos intermedios, entraba en las formas de organizar el reparto patrimonial y la gestión de los bienes en el interior de las familias y en la resolución de sus conflictos, convirtiéndose en el garante del mantenimiento de un cierto equilibrio interno durante, al menos, una generación. El monasterio se iría convirtiendo así en el eje de las transacciones de las comunidades familiares, transformando a veces potenciales enemigos en aliados, imponiendo la jerarquización y clarificación de toda una serie de instancias que participaban en el control de la tierra y en los derechos sobre la misma.

Por otra parte, una actualización constante de las relaciones que se iban anudando en el curso de este proceso era una condición necesaria en el ciclo de la reciprocidad. Las transacciones, que parecen girar siempre en torno a los mismos protagonistas y a los mismos bienes, vinculaban a las partes en un movimiento continuo en el que los contradones no anulaban los dones: los dones creaban deudas a largo plazo que excedían a menudo la duración de la vida de los donantes y los contradones tenían como fin primordial no anular esa deu$\mathrm{da}^{14}$. En este proceso, podemos suponer que el monasterio daba también cierto margen de maniobra a los grupos, teniendo en cuenta — más allá de planteamientos puramente económicos- la estructuralidad de los aspectos eventuales

\footnotetext{
13 «Monacato, linaje y comunidad: un estudio sobre organizaciones colectivas en la sociedad medieval gallega. San Pedro de Ramiranes, . 200-1300)", en Transacciones sin mercado..., Pp. 91-92.

14 Estos son algunos de los mecanismos de los dones y contradones no agonisticos (es decir, no competitivos) que establece GoDELrER, M.: El enigma del don, Madrid, 1998, pp. 75 y 138 en particular: «En esas sociedades, el don no es únicarnente un mecanismo que haga circular los bienes y las personas y asegure con ello su reparto, la redistribución entre los grupos que componen la sociedad. Es también, y más profundamente, la condición de la producción y la reproducción de las relaciones sociales, que constituyen el armazón específico de una sociedad y caracterizan los vínculos que se entablan entre individuos y grupos..» (p. 75).
}

Hispania, LX/1, núm. 204 (2000) 63-101 
y azarosos en la sociedad feudal. El monasterio era además un centro de crédito, renegociaba procesos de endeudamiento, cancelación y nuevos préstamos para compromisos militares. Se vislumbran así elementos importantes en esta relación pero difíciles de cuantificar, como la incapacidad militar de los cenobios, situados entre las comunidades locales y la nobleza guerrera, probablemente muy militarizada en estas zonas como dejan ver sus continuas movilizaciones en la guerra frente a los musulmanes del sur de la Península.

Ahora bien, la reciprocidad generaba diferenciación social porque esta reciprocidad era selectiva, dirigida y desequilibrada. Las relaciones preferenciales entre la institución monástica y algunos miembros de grupos poderosos locales provocaron divisiones internas en estos grupos, acrecentando la tensión entre lo colectivo y lo individual, entre lo cognaticio y nuevas formas de organización familiar, que se estaba lidiando en su interior. De hecho, estas formas variadas de intercambio condujeron a la larga a la ruptura de las comunidades, al debilitamiento de los derechos colectivos y a la individualización en el interior de las familias, en el proceso de vinculación de algunos miembros de estas familias y grupos al monasterio mediante el ejercicio de funciones específicas: como testigos habituales del monasterio en ocasiones, o-de manera más indirectacomo bombres buenos (miembros de la comunidad, que gozaban de prestigio social y que representaban a ésta o a alguna de sus partes en disputas, etc, tanto externas como internas) que actuaban a favor del monasterio aunque se mantuviera la ficción de su vinculación comunitaria. Se trataba, en fin, un aparato que ofrecía consolidación social.

Al final, todos ponían algo en juego, pero se trataba de cosas diferentes y en distintos tiempos. Los nobles comprometían servicios inmediatos, rentas graduales y variables y tierras a largo plazo. Frente a ello, el monasterio renunciaba a acumular bienes a corto plazo. Ofrecía crédito, mediación y paz de manera inmediata y - con su control del tiempo- certidumbre en el largo plazo, creando así una ficción de reciprocidad llena de elementos de poder en la que la representación y las resonancias antiguas que recogen los testimonios escritos parecían responder a prácticas inmutables ${ }^{15}$. Otros elementos de la reciprocidad entre las instituciones eclesiásticas y los poderosos locales, como la amistad, la familiaridad, el vasallaje, implicaban y producían distintos grados de vinculación según las diferentes situaciones en las que los compromisos se establecían. Se trataba propiamente de un intercambio de servicios, el único intercambio capaz - para algunos- de generar reciprocidad ${ }^{16}$.

is Ver ALgazI, G.: «Feigned Reciprocity: Lords, Peasants, and the Afterlife of Medieval Social Strategies», en ALGAZI, G., GroeBNER, V., Jussen, B.: (eds.) Negotiating the Giff, Goettingen, 2000 (en. prensa). Agradecemos al autor su arnabilidad al permitirnos utilizar este trabajo inédito.

16 En relación con esto, véase WACHrEL, N.: «La reciprocité et l'État inca: de Karl Polanyi a John V. Murram, y los comentarios de AUGE, M.: a este artículo en el debate posterior, en Pour the bistoire anthropologique: la notion de reciprocite, en Annales (E.S.C.), 89, 6 (1974), pp. 1346-1355 y $1369-1370$

Hispania, LX/1, núm. 204 (2000) 63-101 


\section{Estrategias de tiempo en las transacciones}

El tiempo - y la posibilidad de la negociación en diferido-, se convirtieron en componentes fundamentales de la relación entre los monasterios y los pequeños poderosos locales, del encadenamiento de actos que constituían la dimensión de interacción social que suponía la reciprocidad y su representación, en la que se vinculaban obligaciones y servicios diversos y heterogéneos ${ }^{17}$. Se establecieron formas específicas, marcadas por el tiempo, mediante las cuales el monasterio de Oseira fue construyendo su poder social frente a los caballeros - milites - y otros grupos destacados en el medio local. Podríamos incluso considerar que estas formas fueron quizás la clave de la diferencia entre esta reciprocidad intraclase y los vínculos a través de los intercambios que obligaron a comunidades campesinas y grupos de beredes — que se estudiarán en la segunda parte de este artículo-, despojados de sus tierras como condición previa al establecimiento de las relaciones con el monasterio.

Un estudio reciente nos ha permitido identificar estos actos marcados por cláusulas temporales como propios de un circuito mediante el cual se consolidaban prácticas extremadamente útiles en los intercambios entre el monasterio de Oseira y grupos dominantes preexistentes en la zona con los que tenía necesariamente que entablar una relación negociada. Eran transacciones -sobre todo donaciones, en ocasiones compraventas y cambios- en las que el donante laico se reservaba el usufructo de forma generalmente vitalicia, si bien en ocasiones a más de una generación ${ }^{18}$.

17 La acción del tiempo es un factor fundamencal en la explicación de los ciclos de reciprocidad para P. Bourdieu, engranajes mecánicos de prácticas obligatorias que sólo existen para la mirada absoluta del espectador, capaz de estat presente en los diferentes momentos del ciclo. El lapso de tiempo interpuesto es lo que permite que el don y el contradon sean vistos y experimentados como un acto inaugural de generosidad, sin pasado ni futuro, es decir, sin cálculo. BOURDIEU, P.: El sentido práctico, Madrid, 1991 ( $1^{2}$ ed. francés I980), especialmente su capítulo 6.

is Hemos utilizado el término transacciones con reserva de usufructo de forma genérica, englobando los prestimonios que responden a una tipología clara con otros documentos en los que las características formales de las concesiones prestimoniales no son tan evidentes pero que hemos considerado vinculados a los otros por su entrega diferida en el tiempo y el tipo de relaciones que se establecen por ello entre otorgante y receptor. La definición institucional de prestimonio como una concesión de tierra con retención del dominio por parte del otorgante pero con la entrega de la posesión y el usufructo temporal o vitalicio que establecía un derecho real de disfrute de una tierra, ha sido enunciada, entre otros, por GARCf́a DE VALDEAVELIANO, L.: «El prestimonio. Contribución al estudio de las manifestaciones del feudalismo en los reinos de León y de Castilla en la Edad Media», Anuario de Historia del Derecho Español, XXV, (1955), pp. 5-122. Con respecto a los prestimonios en Galicia, Ríos RoDRiGuEZ, M.L., "Propiedad de la tierra y relaciones señoriales: el "praestimonium» en Galicia (1150-1350)", Señorí y Feudalismo en la peninsula lbérica. Siglos XII-XIX, vol. III, Zaragoza, 1993, pp. 197-208. Un análisis de carácter más económico del significado de algunas compraventas con reserva de usufructo ya fue realizado en PASTOR, R., RODRíGuEz LóPEZ, A., "Compraventa de tierras en Galicia..», pp. 969-970.

Hispania, LX/1, núm. 204 (2000) 63-101 
Componían actos jurídicos muy complejos. Un miembro o varios de una familia que tenía una cierta categoría social en el marco local y que mantenía una posición previa a la llegada de los monjes cistercienses, entregaba generalmente donaba, pero a veces vendía o cambiaba por otra posesión- una tierra de su propiedad al monasterio de Oseira. Pero se trataba de una entrega parcial, ya que el donante, al traspasar la propiedad de la tierra a los monjes, se reservaba el usufructo de la misma por un período de tiempo definido. En otras ocasiones, era un cambio de propiedades lo que permitía el establecimiento de la relación: un donante laico entregaba una tietra al monasterio y, a cambio, recibía el usufructo de otra - generalmente en un lugar diferente-- para que se beneficiara de la tierra durante su vida con la condición de que volviera a Oseira a su muerte. Este mismo proceso podía también llevarse a cabo con ocasión de una compraventa, evidencia que, por otra parte, nos hace dudar de que sólo las donaciones como actos jurídicos específicos expresaran la reciprocidad entre los poderosos laicos y los eclesiásticos (en el esquema generalmente aceptado, los laicos donan para recibir a cambio beneficios materiales y espirituales procedentes de la posición particular de los clérigos en la sociedad cristiana). En este sentido, la vinculación diferente y diferida que marcan las cláusulas temporales permite incorporar a este circuito otro tipo de intercambios como compraventas, cambios o préstamos ${ }^{19}$.

Las transacciones con reserva de usufructo, operaciones incompletas por definición y que generaban una vinculación personal a largo plazo para ambas partes, disfrazaban bajo una apariencia de toma y daca, de beneficio mutuo, varios aspectos esenciales para ver cómo a través de ellas se ahondaba en el desequilibrio de la relación, siendo el resultado final favorable al cenobio: los donantes que entregaban sus tierras entraban en una relación directa con el monasterio, en sus redes, y se beneficiaban de algunos de los servicios que éste podía ofrecer. Este beneficio inicial concedido al donante establecía un plano de igualdad, contenía el movimiento de solidaridad que se define como uno de los

19 Una visión excesivamente restrictiva del don es común entre los medievalistas. Ver, entre otros muchos, McLaughur, M.: Consorting with Saints. Praying for the dead in medieval France, Ithaca, 1994. En este - por otra parte interesante - trabajo, se diferencia una venca, como un intercambio de propiedad en sí mismo, de una donación, como un intercambio de propiedad destinado a promover la vinculación social entre las dos partes implicadas. De esta manera, una compra puede desarrollarse sólo en un momento mientras que una donación intenta crear o mantener una relación más duradera. Los actos de comprar y vender conllevan relativamente poco significado social, mientras que los actos de dar o recibir dones estan llenos de tal significado, un objeto comprado tiene sólo su propia identidad, mientras que un don tiene también una identidad social, rexiene su asociación con el donante una vez que ha cambiado de manos, sirviendo de recordatorio de la relación entre los dos (p. 139). No obstante esזa crítica, hay muchos aspeccos de interés relativos al acto de dar, que considera como la función ritual propia de los laicos, definitoria de su posición dentro de la comunidad. Una de las funciones de los laicos era dar la ofrenda en las misas y un termino común para designar a los laicos eta offerenter, servidores de Dios y de los santos y por ello miembros de la comunidad agrupada en torno al altar (p. 13I). 
componentes necesarios del acto de donar. Ahora bien, la superioridad, el otro componente del acto de donar para $\mathbf{M}$. Godelier, quedaba muy diluído a primera vista, ya que ambas partes - los pequeños nobles y el monasterio- entregaban algo: unos la tierra y los otros, a continuación, el usufructo de la misma a los primeros ${ }^{20}$. La compensación en la relación parecía ser primordial. Sin embargo, la cláusula temporal terminaba estableciendo la jerarquía, al comprometer a medio o largo plazo la reproducción social de los grupos familiares y originar vinculaciones personales que transformaban la relación de estos grupos con los cistercienses, incorporando además a sus diferentes miembros en sucesivas generaciones ${ }^{21}$.

Basten algunos ejemplos ${ }^{22}$. Sabernos que una relación de estas características vinculó a Oseira familias de caballeros menores titulares de tierras dispersas y de derechos disputados entre ellos, que en algunas ocasiones ostentaban cargos políticos en un nivel local ${ }^{23}$. Gracias a ello, consiguieron a mediados del XIII garantizar el disfrute temporal de sus posesiones. Pero los plazos estaban claramente estipulados. En 1254, Arias Pérez de Tabulata, miembro de una de estas familias, vendió a Oseira un casal por el que recibió 500 sueldos. Quedaba en sus manos durante su vida a cambio de entregar una cantidad de pan al

20 GODELIER, M.: El enigma del don..: «Donar parece instizuir simultáneamente una doble relación entre el que dona y el que recibe. Una relación de solidaridad, ya que el donante comparte to que tiene, o lo que es, con aquel al que dona, y una relación de superioridad, ya que el que recibe el don y lo acepta contrae una deuda con aquel que se lo ha donado. Por medio de esta deuda, se convierte en su deudor y por ello se halla hasta cierto punto bajo su autoridad, al menos hasta que no haya edevuelto" lo que se le donó. Así pues, donar parece instaurar una diferencia y una desigualdad de estatus encre donante y donarario, una desigualdad que en ciercas circunstancias puede transformarse en jerarquia: si ésta ya existía previamente entre ellos, el don viene tanto a expresarla como a legicimarla. De este modo, dos movimientos opuestos quedan contenidos en un solo y mismo acto. El don aproxima a los protagonistas porque se constituye en reparto y los aleja socialmente porque hace de uno el deudor de otro», p. 25 .

21 El relieve concedido al reemplazo generacional puede enlazar con los nuevos enfoques en la antropología que privilegian el proceso de reemplazo como marco en el que hay que analizar la norma de reciprocidad si se analizan las transacciones en el largo plazo. Cf. A. WEINER, Inalienable Possersions. The Paradox of Keeping while Giving. Berkeley/Los Angeles/Oxford, 1992 y también su artículo previo, «Reproduction: a Replacement for Reciprocity», American Ethnologitt, 7, 1 (1980), pp. 71-85. La importancia del reemplazo fue puesta de relieve en PASTOR, R, ALFONSo ANTón, I., RodrígueZ LópeZ A., y SÁNCHEZ LEÓN, P.: Poder monástico y grupos domésticos en la Galicia Foral (siglos XIII-XV), Madrid, 1990.

22 El trabajo documental minucioso de reconstrucción de las familias y patrimonios sobre el que se apoyan las reflexiones que siguen, puede consultarse en RODRÍGuEZ LóPEZ, A.: en Transacciones sin mercado....

${ }^{23}$ Casi siempre se definen por el ejercicio de funciones militares, son milites generalmente y sólo en algunas ocasiones domini, aunque -en un proceso bastante general con respecto a grupos de caballeros menores- están casados con mujeres que sí reciben la denominación de dominae, indicio de una posición social elevada en el marco local. Este fenómeno se comprueba con frecuencia también fuera del marco gallego. CE. BouCHARD, C.B.: Op.cit. p. 168.

Hispania, LX/1, núm. 204 (2000) 63-10I 
año ${ }^{24}$. A numerosas ventas y donaciones de este tenor se referirán los testamentos de este caballero (tres entre 1252 y 1257), que delatan la existencia de una complicada maraña familiar y la entrada diferida de la institución eclesiástica en ella. Se comprueba, por ejemplo, que la mayor parte de los bienes del caballero acabarán finalmente en manos de Oseira, tras un período transitorio en el que se regulaba la posesión dentro de la familia mediante fórmulas de reserva de usufructo que precisaban la mediación monástica: en la práctica, la pérdida de derechos de los hijos mayores sobre las propiedades de Arias Pérez, a favor de un menor tutelado por el abad de Oseira, beneficiario real de la gestión del patrimonio.

La certidumbre se erigía en contradon monástico, la certidumbre que sólo podía ser garantizada por una institución sin tiempo, que es lo mismo que decir con todo el tiempo. Oseira parece asumir una función de organización de estas complejas posesiones y de garante del mantenimiento de las mismas durante una generación, lo que permitía estabilizar patrimonios disputados y clarificar jurisdiscciones muy compartimentadas. De esta manera, los donantes se beneficiaban del respaldo de la institución y los monjes se aseguraban el disfrute de un bien en el futuro que les facilitaba ir penetrando en las redes sociales de los grupos locales. Pero no cabe duda, y esa es la tendencia que refleja la documentación, de que el resultado a medio plazo era la incorporación de los bienes de un sector de la familia al monasterio.

Una de las funciones principales de este tipo de actos jurídicos se correspondía con la consolidación de una política de préstamos, devoluciones y nuevas deudas que creaba vínculos entre deudor y acreedor más allá de la operación puramente económica. Estos vínculos se mantenían de generación en generación ya que los hijos terminaban asumiendo las deudas de los padres y todo el grupo familiar se encontraba de alguna manera implicado. El endeudamiento habitual de estos caballeros para ir en la hueste con sus señores se traducía en las relaciones que se establecían con estos monasterios que actuaban como prestamistas. La continua referencia a estos préstamos de dinero, de los que quedan abundantes datos en los testamentos de los milites, señala la importancia de estos recursos para el mantenimiento de funciones militares de los miembros destacados de estas familias, sujetos a cadenas vasalláticas que no suelen reflejarse en los actos cotidianos que muestra la documentación.

En definitiva, podríamos pensar que con los grupos más claramente destacados en estas comunidades familiares, la relación diferida con el monasterio clarifica derechos y resuelve conflictos gracias a la continuidad que podían ofrecer las instituciones eclesiásticas. Pero la continuidad que se garantizaba a corto plazo, resultaba comprometida a un plazo más largo de forma parcial o total dependiendo de la mayor o menor fuerza de estas familias y el diferente grado

24 Romaní MARTiNez, M.: Colección diplomática..., vol $\mathrm{I}, \mathrm{n}^{\circ} 728$, p. 690. Los testamentos citados a continuación corresponden a los vols. I y $\mathrm{I}$, docs. $\mathrm{n}^{\circ} 683,718,790$.

Hispania, LX/1, núm. 204 (2000) 63-101 
de su consolidación en la zona. Algunas se mantienen. Otras, van diluyéndose frente a la presión de los monjes.

Los conflictos surgían, sin embargo, ante la dificultad para hacer efectivas transacciones pactadas anteriormente, ante las negativas de los descendientes a cumplir las cláusulas de entrega de la tierra a la muerte de los donantes ${ }^{25}$. En 1287 una sentencia regia permitió a los monjes obtener unos casales que habían sido entregados por un caballero ..modo compulsus neccessitate.. casi 30 años antes y que su hija había intentado retener a su muerte ${ }^{26}$. A continuación, se reanudaba la relación, al obtener esta hija como compensación nuevas tierras de Oseira de forma vitalicia.

Otros grupos familiares fueron ascendiendo socialmente al abrigo de las redes del monasterio. No se trataba en este caso de comunidades instaladas en la zona antes de la llegada de los cistercienses y con poder patrimonial y político previo sino de grupos de parentesco con bienes dispersos a los que su vinculación con los monjes les permitió destacarse de su entorno.

Desde finales del siglo XII miembros de un grupo de parientes apellidados Luz realizan intercambios en el interior de la familia. De 1222 es el primer contacto con Oseira que conserva la documentación. Se trata de un cambio que aparentemente reporta escasos beneficios a la familia, una transacción que les obliga a desprenderse de parte de un núcleo central de su patrimonio y a desplazar sus intereses a una nueva zona al sur del monasterio ${ }^{27}$. Pero como contrapartida, a partir de entonces la relación va a ser continua, determinando el ascenso social de algunos miembros de esta familia. Indeterminadas aún, las posibilidades futuras que puede deparar el vínculo ahora instaurado se expresan en el documento: ..ut ego et praedicto filius meus participes simus omnium bonorum quae in praedicto monasterio fiunt vel deinceps fient..., señala la donante acompañada por su hijo.

Pero, como sucede con frecuencia, otros hijos rechazaron el acuerdo. En la resolución de los consiguientes pleitos se pone de relieve el sentido en el que se estaba produciendo la vinculación de la familia Luz con los cistercienses. El monasterio ha seleccionado como interlocutor a uno de sus miembros -el hijo al que se hacía participe de los beneficios futuros- y no al grupo familiar en sí. Los nuevos recursos políticos de éste, procedentes de esta vinculación, le permitieron resolver en su beneficio este conflicto familiar. Pero la resolución, en realidad, era también a favor de los monjes, quienes consiguieron a su vez introducir en el grupo familiar un mediador capaz de defender los intereses monásticos. No parece casual que aquí aparezca por primera vez este hijo, Oveco

\footnotetext{
25. No sólo la muerte (naturalem o civilem, como señala un donante en 1227) obligaba a la entrega de la tierra. También la entrada en alguna institución eclesiástica forzaba el cumplimiento de estas cláusulas temporales.

26 Ibidem, vol. II, $\mathrm{n}^{\circ} 825$ y 1196 .

27 Ibidem, vol.I, $\mathrm{n}^{\circ} 224$, p.. Otros documentos relativos a esta familia: $\mathrm{n}^{\circ} 352,432,471,582$, 586,1021
}

Hispania, LX/1, núm. 204 (2000) 63-101 
Luz, calificado como caballero. La naturaleza del vínculo se comprende mejor años después: el monasterio ha promocionado e incorporado a este personaje a su círculo de caballeros amigos, los que testifican y hacen servicios - no sabemos cuáles- para él. Parece, incluso, que en su ascenso social amparado por el monasterio este caballero va arrastrando a algunos de sus parientes. Pero también se intuyen algunas de las contrapartidas que impone la entrada de estos milites en una cierta dependencia de Oseira, como - por ejemplo, en 1246estar obligados a entregar sus tierras patrimoniales a cambio de otras más alejadas de sus intereses atendiendo a las necesidades de la gestión monástica.

La relación ventajosa con Oseira, en definitiva, no supuso para esta familia un incremento patrimonial, del que apenas hay vestigios, sino fundamentalmente la posibilidad de fijarse localmente como un grupo intermedio y favorecer el ascenso de algunos de sus miembros en la función militar. Pero como contrapartida, esta relaciones preferenciales con ciertos individuos incidían de forma dialéctica en la estructura de grupos de parentesco que se encontraban inmersos en procesos de transformación a partir de estructuras cognaticias, definiendo jerarquías internas, al seleccionar el abad y los monjes como interlocutores algunos de ellos y no otros, contribuyendo a debilitar en última instancia su cohesión y sus derechos colectivos. El monasterio aparece así como un factor de individualización de relaciones, un aparato que ofrecía consolidación social. A cambio, Oseira pasaba a ser el eje de las transacciones en el interior de la comunidad familiar y terminaba situándose, a medio plazo, en su centro mismo.

\section{Compromisos, deberes y servicios.}

Las transacciones con reserva de usufructo permitieron a las instituciones eclesiásticas ganar con el tiempo. Renunciaron a acumular propiedades de forma inmediata y entraron en una dinámica de esperar a que se cumplieran las cláusulas temporales para obtener las posesiones acordadas. Pero también se contemplaban ganacias económicas en el proceso. El casal que debía entregar a Oseira a su muerte el miles Juan Pérez, apodado de Manus - -según acordaron en 1258 como hemos visto- tenía que estar populatum para que el monasterio lo recibiera con la mejora de los animales de labranza aportados por el donante. En otros casos se especifica incluso cuáles tienen que ser estos animales: al devolver varios casales tras tenerlos de por vida, una pareja debía entregar en 1265 duos boves, duas vacas et VI rechelos en uno y duos boves et unam vacam en el otro ${ }^{28}$.

Cabe pensar que existían, a su vez, contrapartidas económicas para estos pequeños nobles, como el aumento de las rentas que percibían al ser integradas sus posesiones en el seno de una comunidad monástica, rentas que no existían

\footnotetext{
28 Ibidem, vol. II, n 922, pp. 878-9.
} 
fuera del mundo eclesiástico - diezmos, primicias, etc- y de las que ahora podrían beneficiarse. Podría pensarse además que la transacción implicaba la percepción de los derechos jurisdiccionales correspondientes si estos casales y heredades estaban situados en el interior de los cotos de los monasterios ${ }^{29}$. En algunos casos, incluso, el monasterio parece encargarse en la práctica de la gestión de estas propiedades que aún no son suyas, recibiendo a cambio la percepción de sus rentas, no sabemos si total o parcialmente. Pequeños indicios llevan a considerar esa vía. En 1279, por ejemplo, el abad de Oseira transforma en vitalicio un contrato de foro que quizás era de mayor duración y que los foreros tenían ya de una domina vinculada al cenobio por medio de intercambios diferidos. La renta, probablemente también aumentada como consecuencia del cambio de la temporalidad del contrato, debía ser ahora entregada a Oseira ${ }^{30}$.

La importancia de los compromisos se manifestaba en la necesidad de proteger los acuerdos y dar garantías sobre su cumplimiento. En buen número de estas transacciones, tanto con los grupos más consolidados como con los que se van destacando entonces, los vendedores o donantes se comprometían además a defendere et amparare al monasterio con todos sus bienes, los que tenían y los que llegaran a tener en el futuro. Outorgamos de vos anparar por nos et por quanto nos avemos et devemos por aver: esto prometían al monasterio en 1282 Diego García, caballero de Moreiras, y su mujer. Esta cláusula era la expresión de un compromiso por parte de los otorgantes, que podía implicar el pago de rentas y jurisdicciones debidas a otros o responder ante la justicia u otras autoridades en caso de reclamación de terceros, generalmente sus propios parientes. Así se comprueba, por ejemplo, en una venta a Oseira en 1279 , en la que los vendedores prometen .. vos a anparar et a deffender de nossos fillos que non foron pressentes. ${ }^{31}$.

Los documentos que formalizaba estas relaciones entre laicos y eclesiásticos inclúan toda una serie de obligaciones mutuas - menos materiales a primera vista- que tejían los hilos de la reciprocidad. Los laicos tenían que ser fieles vasallos del monasterio pero a cambio podían convertirse en sus familiares y recibir sepultura en él, es decir, compartir los beneficios espirituales que se asociaban a los miembros de la comunidad monástica ${ }^{32}$. En la década de 1170 ,

29 Esta es la hipótesis que desarrolla Ríos RoDRÍGUEZ, M.L.: «Estrategias señoriales en Galicia: Las instituciones eclesiásticas y sus telaciones contractuales con la nobleza laica (I 150-1350)", en Poder y sociedad en la Galicia medieval, Santiago de Compostela, 1992, pp. 175-189.

30 Colección diplomática... vol. II, n 979, pp. 932-3.

31 Ibidem, $\mathrm{n}^{\circ}$ I 134, p. 1078. Aunque para Oseira no tenemos tan específicadas muchas de estas obligaciones, así figuran para el cercano monasterio de Montederramo, en cuya documentación las claúsulas de defensa y amparo son muy abundantes. Ver PASCUA ECHEGARAY, E.: «Vasallos y aliados con conflictos: las relaciones entre Santa María de Montederramo y la sociedad local gallega del siglo XIII», Transacciones sin mercado..., pp. 35-90.

32 E. Pascua hace importantes consideraciones sobre el vasallaje y la dependencia no como fruto de la sujección unilateral de grupos bajo el empuje monástico sino de la negociación de ciertos sectores con un aparato que ofrecía consolidación social. Transacciones sin mercado... 
Pedro Martínez, llamado juglar (cognomento ioculator) es recibido por Oseira in fratrem et socium nostrum para que pudiera beneficiarse siempre de las oraciones de los monjes, autorizándole además a que tomara el hábito de la orden cuando quisiera, dado que había entregado al cenobio una heredad, que mantendría en sus manos de forma vitalicia. Tras su muerte, se estipulaba que su hijo podría disfrutar la heredad. Pero - y esto es importante- la condición de la posesión de la tierra es ya distinta. Ahora este hijo la tendrá non pro iure, set ut inde fideliter monasterio serviat ${ }^{33}$.

En ocasiones, la familiaritas con el monasterio parece más una cláusula impuesta por éste para vincular más estrechamente a algunos laicos con los tenía conflictos que un beneficio solicitado por éstos. En las décadas finales del siglo XII — con objeto de conseguir una mayor homogeneidad en la implantación monástica- se produjo un desalojo parcial de grupos familiares preexistentes en la zona vitícola de Oseira que posteriormente dió lugar a conflictos. Una familia, compuesta de varios hermanos y de sus hijos respectivos vendió a Oseira en 1152 importantes heredades patrimoniales, recibidas de padres y abuelos, en el lugar de Guitar, en la ribera del Miño ${ }^{34}$. Cuatro años después, en 1156, se produjo un proceso similar de adquisición en la misma zona por parte de los monjes, mediante un cambio con otro grupo familiar, compuesto también por tres hermanos y sus hijos. Como en el caso anterior, Oseira se hizo con una heredad aún sin disgregar por sucesivas herencias en la que varios hermanos compartían la propiedad. Pese a esta aparente similitud, las relaciones entabladas con estos dos grupos fueron diferentes, y así se manifiesta en la reciprocidad monástica.

Un documento de 1174 desvela el enfrentamiento con Oseira de Ios hijos de los primeros vendedores en Guitar, un total de 11 hermanos y primos, quienes habían reclamado a Oseira el precio convenido por sus padres. Tras una sentencia favorable a Oseira, este grupo de parientes no había cesado - según reconocen ellos mismos- de inquietare el lugar. Ahora, en 1174, ..Deo annuente et inspirante in cordibus nostris videntes quod rem in iustam faceremus coadunati.. rectifican su actitud y llegan a un acuerdo con Oseira $\longrightarrow$ más bien aceptan las condiciones impuestas por el monasterio-: se hacen familiares de los monjes, se someten a su protección y se comprometen a ser amici fidelis, entregarles sus bienes y servirles. A pesar de la retórica de la protección y del aparente beneficio de la familiaritas, parecía tratarse de un sometimiento en toda la regla ${ }^{35}$.

33 Ibidem, vol. I, $\mathrm{n}^{0} 65, \mathrm{p} .78$.

${ }_{34}$ Los documentos relacionados con el lugar de Guitar en Ibidem, vol. I, $\mathrm{n}^{\circ} 24,32,54,63,110$.

35 Ut nos reciperent in capitulo pro familiares et ut nos aliquid adiuverent in angustiis nostris si forte nobis evenerit. Nos vero pro inde promittimus eis esse familiares et amici fideles et de bona nostra eis dare et eos servire in vita nostra et in obitu... En 1204 Oseira emitió un documento similar al de treinta años antes, probablemente relacionado con el mismo grupo familiar que el primero. Se resuelve en los mismos términos. Los ahora denominados milites abandonan sus reclamaciones en Guitar y se hacen familiares del monasterio. 
La relación con Oseira de Urraca Yáñez, domina, miembro de la familia que había cambiado propiedades con Oseira en Guitar en 1156, era diferente. Su mayordomo había sido uno de los pesquisidores en el pleito favorable a Oseira que recogía el documento de 1174 y es evidente que había entrado en la red de alianzas del monasterio. En 1282 hizo una donación a Oseira, pidiendo que a cambio los monjes celebrasen sufragios y aniversarios por ella y por sus parientes más cercanos. Parece claro que el acuerdo anterior al que había llegado con la institución monástica, el cambio de algunas propiedades que en principio no beneficiaba patrimonialmente a esta domina, le había reportado otra serie de ventajas nada desdeñables: básicamente, ser destacada por el monasterio para la intervención en los conflictos en la zona y la posibilidad de sostener una posición por encima de los demás propietarios que habían vendido sus tierras al cenobio, actuando mediante sus dependientes al lado de los monjes. Posiblemente por esa razón, no entraba en la familiaridad de Oseira de la misma manera que los demás.

El amor circulaba por estas transacciones de forma generalizada. Aunque las referencias al amor et gracia con que los monjes de Oseira beneficiaban a sus vecinos son abundantes, algunas de ellas reflejan realmente una posición particular de ciertos personajes en el entorno monástico. En 1287 un caballero había sido instituído como tercer mediador en una avenencia en el caso de que los hombres buenos que representaban a ambas partes -el monasterio y una importante farmilia de milites, los Tabulata - no se pusieran de acuerdo ${ }^{36}$. Este mediador, Gil Martínez, caballero de Olvan, era con certeza un personaje cetcano a los monjes que gozaba de una posición privilegiada. Así se expresa en 1291 el abad de Oseira cuando, en un cambio con reserva de usufructo, se indica la motivación de la transacción: porque sodes omees que amamos. La cercanía que refleja el amor del monasterio se relacionaba con las funciones de bombre bueno (representante de la comunidad) que permitieron a este caballero actuar reiteradamente a favor de Oseira. El posterior testamento de su hija confirma que mantiene una estrecha vinculación espiritual con los monjes -construye y dota una capilla en el monasterio en memoria de sus padres y se manda enterrar en ella a su muerte-, su posición social es elevada - mujer de un caballero y hermana de otro- y sus posesiones, recibidas de su padre, son numerosas y dispersas, como se verá años después en el pleito entre sus herederos y los cistercienses.

La condición de bombre bueno que reflejan algunos documentos de Oseira hace dudar de que se trate sólo, como se suele aceptar, de una emanación de la comunidad que elige a sus propios representantes. Parece, más bien, una fun-

36 Tampoco la elección de uno de los hombres buenos por Arias Pérez de Tabulata y sus herederos parece casual: se trata de García Gómez de Moreiras, miembro de un grupo de milites vinculados por parentesco y dependientes de aquellos. Ibidem, vol. II, $\mathrm{n}^{\circ} 1193$. Los otros documentos relacionados con el caballero de Olvan: $n^{\circ} 1227$ y 1239 y con su hija, vol. III, $n^{\circ} 1614,1615$.

Hispania, LX/1, núm. 204 (2000) 63-101 
ción estrechamente imbricada en el entramado de relaciones personales que vinculan entre sí a los miembros de los grupos sociales en el entorno de Oseira y que, a su vez, vinculan a éstos con la propia organización monástica. La familiaridad y los beneficios espirituales que corresponden son de muy distinto grado a lo que acontece en otras ocasiones, cuando la reciprocidad en forma de servicios espirituales disfraza una coacción - no sabemos si percibida como tal-a los familiares del monasterio.

Pero una significación más real de los vínculos que establecían los intercambios diferidos y las transacciones con reserva de usufructo - $y$ la realidad de una reciprocidad desequilibrada - se percibía en las cláusulas de los acuerdos que cortaban la posibilidad de cualquier otra transferencia de la tierra comprometida. No vender, no enajenar, no pignorar son obligaciones que se repiten en general en todas las operaciones entre las comunidades locales y las instituciones monásticas y la interpretación general incide en la necesidad de éstas de controlar la tierra y sus posesores ${ }^{37}$. Esto es evidentemente así, pero también hay que tener en cuenta que, al prolongarse estas condiciones en el tiempo de una vida —l período en que podían disfrutar los donantes de ellas antes de su entrega al monasterio-, la situación se transformaba. En un mundo en que las transferencias de tierra permitían establecer las relaciones sociales y construían identidades personales y colectivas, la prohibición del intercambio durante una serie de años bloqueaba a largo plazo las posibilidades de nuevas relaciones de estos grupos. Al quedar el objeto del intercambio preso en el tiempo, se afirmaba - diferida y disfrazada - la superioridad de la institución monástica.

Incluso podríamos alegar -parafraseando a antropólogos como $\mathrm{A}$. Weiner y $\mathrm{M}$. Godelier ${ }^{38}$ - que lo que pone en marcha el sistema de intercambio no son las cosas que se dan sino las que se guardan. Un análisis minucioso de los abundantes intercambios de Oseira revela - sorprendentemente- la poca movilidad real de la tierra. La tierra circula virtualmente pero apenas cambia de manos, se sitúa en realidad al margen del mercado. La tierra, el objeto de las transacciones, genera vínculos específicos y circula con un tempo propio - ni tan rápido ni tan fácilmente-, diferente a la manera en que se produce la circulación de otros bienes. Los flujos de tierra sancionan relaciones sociales y, a su vez, están condicionados por ellas ${ }^{39}$.

37 La importancia del control, más que de la propiedad, es algo que no se destaca nunca lo suficiente. Remitimos a una cita de una obra clásica: Homans, C.G.: English Villagers in the Thirteenth Century, Harvard, 1942: «En cada sociedad hay hombres que controlan más comida, ropas y otras formas de riqueza producida por la sociedad que otros. La palabra control se usa aquí deliberadamente: desde muchos puntos de vista,el control de la riqueza es más importante que su mera posesión"

38 WeINer, A.: Inalienable Possessions. The Paradox of Keeping wbile Giving, como a GoDELIER, M.: El enigma del don. En el proceso de producción y reproducción de jerarquías entre individuos o grupos, las estrategias de donar y de guardar desempeñan roles distintos pero a su vez complementarios.

39 Creemos que algunas aportaciones de la antropología sobre el intercambio económico y las relaciones de propiedad pueden ser reveladoras para los medievalistas, en particular en lo que se 
En el caso de los grupos de caballeros y de miembros destacados de las comunidades en el entorno del monasterio de Oseira, la tierra genera relación entre las personas y no grandes cambios patrimoniales en sí mismos. En realidad, a través de la tierra se negocian derechos y obligaciones establecidos en distintos plazos, mientras que lo que realmente circula de manera más fluída entre unos y otros es la renta que se obtiene de la tierra, que se aumenta o se renegocia dependiendo de diversas circunstancias. Sólo tomando estos aspectos paradójicos en consideración se pueden explicar complejas transacciones que recoge el cartulario de Oseira.

En 1252, el caballero Atias Pérez de Tabulata, se comprometía en su testamento a saldar sus deudas anteriores con Oseira, recibiendo a cambio un préstamo sobre su casal de Palacios, en tierra de Asma —en el que moraba un tal Pedro Dorado-, con la condición de que si no lo devolvía en la fecha fijada perdería la propiedad del bien aunque podría mantener el usufructo de forma vitalicia y recibir nuevos préstamos. En otro de sus testamentos, unos años después, el casal de Palacios se entregaba directamente a Oseira con la condición de que algunos parientes recibieran una renta de él. En 1260, Arias Pérez negociaba de nuevo con Oseira sobre esta propiedad, al donarla a cambio de un préstamo de 500 sueldos. No obstante, la vinculación con el casal se mantenía mediante la reserva del usufructo por parte del caballero, e incluso se incorporan nuevas propiedades a esta forma de relación al recibir éste de Oseira otros casales de forma vitalicia. Años después, sin embargo, este casal de Palacios seguía en manos de Arias Pérez: en 1264 lo compromete - con otras propiedades - a su mujer en calidad de arras, lo que paradójicamente no le impide venderlo al día siguiente, con los demás bienes de las arras, a un arcediano de Lugo.

Esta tierra reaparece en 1279 , cuando don Arias Pérez de Tabulata recibe del abad una renta de pan sobre los frutos del casal de Palacios, ahora ya propiedad de Oseira. Parece, sin embargo, que ha llegado a Oseira por vía de otros miembros de la familia. Sabemos que en 1272 doña María Gil de Tabulata, había donado a los monjes su casal de Palacios, que era de Pedro Dorado, quien ya aparecía como morador del mismo en el primer testamento de Arias Pérez.

Es acertado interpretar la trayectoria de bienes como este casal de Palacios poniendo de manifiesto la dificultad para clarificar derechos de propiedad y posesión entre los diversos poderes locales en la sociedad feudal. Pero se puede ir más allá y considerar que la importancia de algunos bienes no era sólo su valor en una transacción sino también su capacidad de ser un objeto de negociación que generaba y era susceptible de modificar la vinculación entre las instituciones monásticas y sus vecinos poderosos locales, la relación entre per-

\footnotetext{
refiere a la concepción de las relaciones de propiedad corno relaciones sociales a través de las que se construyen identidades personales y colectivas. Especialmente, HANN, C.M.: (ed.), Property relations. Renewing the antbropological tradition, Cambridge, 1998; APPADURAI, A.: (ed.), The social life of things. Commodities in cultural perspectives...
}

Hípaniat, LX/1, núm. 204 (2000) 63-101 
sonas y cosas pero también - y esencialmente- entre personas. Aún después de haberlos donado a los cistercienses, los milites y sus familias seguían ligados a estos bienes ${ }^{40}$.

\section{RECIPROCIDADES DESIGUAIES ENTRE GRUPOS CON GRAN DISTANCIA SOCIAL}

El estudio pormenorizado de la documentación del monasterio de Oseira desde el final del siglo XII proporciona datos suficientes para adentrarnos en los problemas concretos de la reciprocidad entre el monasterio y las comunidades campesinas como conjunto por una parte y, por otra, entre el monasterio y los grupos domésticos que gozaban de contratos de foro en el amplio territorio que ocupó Oseira y que tuvo como origen donaciones reales. Un punto de partida básico es interpretar qué tipo de relaciones se establecieron en esa importante zona de Galicia meridional, poco estructurada política y socialmente, en el siglo en que se va formando y consolidando el poder feudal, tanto el clerical como el laico.

El concepto de reciprocidad - en su multiplicidad y con las variantes que explicaremos- es fundamental dado que analizamos relaciones sociales, grupales o individuales en las que interviene de manera imprescindible un orden moral. Ante la nueva situación de dependencia feudal, persistieron con fuerza formas de reciprocidad interna de las comunidades campesinas $y$, al mismo tiempo, se fueron creando otros cauces de relación entre campesinos y señores que conservaron importantes expresiones de esas reciprocidades internas u horizontales si bien modificadas por la intromisión señorial. Se constituyeron así nuevas formas de reciprocidades, verticales, y desequilibradas, que vamos a presentar ahora desde nuevos ángulos. Estas formas nuevas de reciprocidad cristalizaron al producirse importantes cambios en el orden institucional de la sociedad, cuando se estaban trabando las relaciones feudales y construyendo el sistema en complejas y variadas direcciones.

Podría suponerse - al menos es lo que refleja la documentación, que es toda monacal y puede ocultar situaciones no gratas para el cenobio- que los señores al imponer sus formas de dominación coactiva y vertical lo hicieron en términos pactistas y pacíficos, apoyándose para ello en el consenso básico de

40 Los documentos relativos al casal de Palacios en Colección diplomática... $\mathrm{n}^{\circ} 718,790,876$, $911,912,1015,1139$. Conviene recordar aquú la vinculación de los objetos a sus primeros donantes y las numerosas páginas que se han escrito en los escudios antropológicos sobre el espíritu de la cosa que se da desde Mauss, M.: "Ensayo sobre el don. Motivo y forma del cambio en las sociedades primitivas", (1923), en Saciología y Antropologia, Madrid, 1971. Ver también SAHLINS, M.: Economia de la Edad de Piedra, Madrid, 1977, en particular el Capítulo 4, «El espíritu del don", pp. 167-202. La ideatificación de la tierra con sus antiguos propietarios en la Edad Media ha sido puesta de relieve, entre orros, por Rosenwein, B.: To be the Neigbbor of Saint Peter. The Social Meaning of Cluny's Property, 909-1049, Ithaca-Londres, 1989. 
paz, amor y amistad predicado por la doctrina cristiana que ellos enseñaban y que las comunidades aceptaban, aunque desconocemos en qué grado y de qué manera. Pero ¿Hasta qué punto los campesinos aceptaron los pactos acordados con los señores como una reciprocidad o un intercambio equitativo y justo? ¿Hasta qué punto se consideraban compensados cuando daban bienes de producción y de trabajo a cambio de amor y protección, conceptos cuyo alcance no queda bien definido y que pudieron tener contenidos diversos y ambigüos? ¿Variaba la aceptación campesina sobre el valor del pacto cuando la protección que les prometía el cenobio se definía concretamente - como en el ejemplo que se presenta luego- cuando se establecía con respecto a otros elementos sociales agresivos para ellos, como los caballeros, a quienes el monasterio podía contener con medios diversos que no estaban a su alcance?¿Hasta dónde $\rightarrow$ sin dudar de su existencia y fuerza - la fe en la salvación del alma, las ideas religiosas, espirituales y morales intervinieron plenamente en la justificación de los acuerdos? ¿Cómo puede apreciarse el peso del orden moral y el del interés económico copartícipes en las transacciones recíprocas?

No cabe duda de que los contenidos concretos de los dones eran absolutamente distintos y de diversa naturaleza que los contradones para las partes comprometidas en los pactos, comunidades o grupos domésticos y señores. Parece claro que estas reciprocidades debían generar tensiones sociales. En la práctica, las partes evaluaban sus intercambios, si eran equitativos o equivalentes en la consideración de ambas partes, aunque podía ocurrir - y estimamos por múltiples manifestaciones posteriores que así era- que la parte campesina estuviera en desacuerdo, al menos parcialmente, a pesar de que se viera obligada a aceptar lo que el poder monacal le imponía.

Dos relevantes aspectos estaban ineludiblemente presentes en esos intercambios. Por un lado, la conciencia concreta y tangible para los campesinos de que se comprometian a entregar una parte importante de su producción de bienes de consumo y una parte a veces considerable de trabajo directo. Por otro, que en su religiosidad, también indiscutible, operaban ideas o creencias contradictorias propias de la doctrina cristiana que recibian. Porque si bien en esa doctrina el amor entre unos y otros, la caridad y la solidaridad constituían una de sus vertebraciones más importantes, también actuaban, en contraste, los temores al infierno, a la pérdida de la salvación del alma, la culpa por los pecados cometidos, el temor a la excomunión, a la marginación de la sociedad cristiana ${ }^{41}$. Persistía la base arcaica de la cultura popular -en parte deformada y relegada por la ideología dominante- expresada en pequeña medida en los textos medievales a causa de la cristianización y del establecimiento de controles espirituales por

11 Ponemos sólo un ejemplo del cartulario de Oseira, vol. II, n ${ }^{0} 1244$, p. 1181. En el año 1294 un caballero retira la demanda que había presentado contra el abad de Oseira por razón de unas heredades que un tío suyo diera al monasterio. Dice retirarla porque ".. temendome de mia alma et avendo medo....”

Hispania, LX/1, núm. 204 (2000) 63-101 
parte de la Iglesia ${ }^{42}$, aunque estas «mayorías silenciosas", estos bomines illiterati et idiotae, no podían vencer el respeto que les imponía el desconocimiento directo de las Escrituras y de los catecismos, de la lengua oficial, de la escritura, de la jurisprudencia, de las formas de ejercicio del derecho y de la organización eclesiástica. Hay que tener también en cuenta las formas de dominio espiritual, de acción a través del imaginario colectivo e individual, que -compartidas por los miembros de la Iglesia - facilitaron a las instituciones eclesiásticas el ejercicio de presiones coactivas tendentes a permitirle una importante acumulación de poder material, espiritual y político, ya que, de haber funcionado sólo las formas religiosas de amor y solidaridad, no se habría llegado a tal acumulación ni a una jerarquización ni división tan profunda de la sociedad plenomedieval.

En realidad, lo que se estaba estructurando con estas nuevas relaciones de reciprocidad desigual era una nueva forma de intercambios desiguales, una forma de reproducción social que se inscribía en un sistema de desigualdades. Es muy posible que los campesinos la percibieran aunque es dificil saber cómo la comprendían.

\section{Nuevos contextos, PeRsistencias y cambios. Las COMUNidAdes DE HEREDES Y EL MONASTERIO.}

En los pactos y acuerdos realizados entre comunidades y el cenobio, especialmente en la primera mitad del siglo XIII, dos eran los protagonistas del acuerdo, ambos colectivos y jerarquizados socialmente: las comunidades y los miembros de los monasterios encabezados por su abad. Pactaban por ambos lados personajes precisos, en su propio espacio social, y lo hacían en función de sus posibilidades y de la coyuntura del momento. Pero en estas condiciones jugaban tanto los elementos concretos del presente como otras realidades sociales articuladas en el pasado. Entraban en esta situación en apariencia puntual experiencias anteriores en parte repetidas, conocidas y evaluadas. Se inscribían en un sistema de contextos pasados, seleccionados y transformados por el tamiz del tiempo, es decir, presentes y reelaborados a la vez $z^{43}$. La singularidad de los hechos -en este caso los pactos y contratos- realizados en un momento preciso, la manera propia de expresar y organizar su historicidad, residía en el efecto de tensión que generaba la contemporaneidad de actitudes heredadas del pasado y los compromisos que se establecían inducidos por los nuevos envites ${ }^{44}$.

Esos actos protagonizados por individuos o más frecuentemente por conjuntos comunitarios o familiares, cobraban imprescindible significado si se los

\footnotetext{
42 Conceptos de LE GOFF, J.: en «Culture cléricale et tradition folklotiques dans la civilisation mérovingienne", en, Nivetux de culture et groupes sociaux, París-La Haye, 967, p. 21.

43 Como lo llama LEVI, G.: La berencia inmaterial., p. 13.

94 BENSA, A.: «De la microhistoire, vers une anthropologie critique» en REvel, J.: (dir.) Jeux d'écbelles. La micro-analyre à lexpérience, Paris, 1996, p. 54.
} 
vincula a las posiciones sociales que ocupaban en su momento de protagonismo, que sin duda condicionaban el modo de intercambio ${ }^{45}$. El peso de las actitudes prescriptivas -que procedían de las normas preestablecidas-y el de los actos performativos capaces de generar por sí mismos nuevos contextos ${ }^{46}$, estuvieron presentes en los pactos, dado que las posibilidades de los acuerdos estuvieron condicionadas especialmente por el debilitamiento de la mayoría de los grupos familiares que formaban las comunidades y porque, pese a ello, se conservaban lazos comunitarios y organizaciones familiares lo suficientemente fuertes como para no diluirse ni perder identidad ante los nuevos contextos.

Esos acuerdos, pactos y contratos señalan momentos cruciales en la historia de sus protagonistas. Mediante ellos se entablaban relaciones de reciprocidad vertical que comprometían no solamente a las partes actuantes en el momento, sus hijos o sus nietos, sino incluso a las generaciones posteriores a perpetuidad. El momento del pacto dividía los tiempos de ambas partes. Por un lado, el monasterio se avenía a mantener los acuerdos por tiempos largos, que podían ir de dos o tres generaciones en adelante. Pero el mismo monasterio contaba siempre con un tiempo más largo, dado que —como ya hemos destacado-, el Cister como institución eclesiástica podía contar en la realidad y en su imaginario con una continuidad secular de muy larga duración. Por su parte, los campesinos comprometían el futuro de sus hijos y nietos, aunque tenían conciencia de los posibles avatares familiares y de las también posibles rupturas, o desvia-

45 Durkheim, siguiendo a Marx, denunció la ideología individualista y psicologista que antepone la autonomía del sujeto por delante de su medio social de origen. "En tant que méthode cette vulgate déterministe —qui, dans son acception la plus générale, n'a pu être infirmée-conduit le sociologue (et l'historien) à décrire tout espace social comme un systèrne differencié de status, clé interpretative des agissements de ses membres: les propos de uns et des autres en effet compris comme de points de vue que reflètent des expèriences sociales du monde aussi diverses que la morphologie est hétérogène et divisée en plusieur sous-ensembles permanents (classes, ordres, catégories, strates, etc)", glosa de DuRkheim, E.: Les regles de la méthode sociologique, París, 1963 (1er ed. 1895).

46 Bourdieu, P.: en Cosas Dichas, Buenos Aires, 1988, recoge estos conceptos y explica los cambios: «En primer término, como toda forma de discurso performativo, el poder simbólico debe estar fundado sobre la posesión de un capital simbólico. El poder de imponer a los otros espiritus una visión antigua o nueva, de las divisiones sociales depende de la autoridad social adquirida en las luchas anteriores. El capital simbólico es un crédito, es el poder impartido a aquellos que obtuvieron suficiente reconocimiento para estar en condiciones de imponer el reconocimiento: así el poder de constitución, poder de hacer un nuevo grupo, por la movilización, o de hacerlo existir por procuración, hablando por él en tanto mensajero autorizado, no puede ser obtenido sino al término de un largo proceso de institucionalización, al término del cual es instituido un mandatario que recibe del grupo el poder de hacer el grupo. En segundo zérmino, la eficacia simbólica depende del grado en el que la visión propuesta escá fundada en la realidad. Tiene tantas más posibilidades de éxito cuanto más fundada está en la realidad: es decir en las finalidades objetivas entre las personas que se trata de juntar». El concepto de perfomativo procedente de la lingǘstica está desatrollado en los términos que nos interesan por SAHLINS, M.: en Islas de bistoria. La muente del capitan Cook. Metáfora, antropologia e bistoria, Barcelona, 1988, pp. 42-46. 
ciones de las continuidades temporales programadas. ${ }^{47}$ En definitiva, la expresión temporal del compromiso de las partes estaba señalando que se ponderaba en los acuerdos la relación de reciprocidad y de mutuo acercamiento social como algo duradero - extendido en un tiempo seguramente percibido como muy largo, imaginado o programado, como quiera interpretarse-, que se superponía a los intereses puramente económicos de los que, además, no se tenían en cuenta sus posibles variaciones.

Pero no debe pensarse que desde el momento del pacto se establecían ciclos de reciprocidad, dado que bastaba que sucediera algo distinto a lo que querían las leyes mecánicas de un ciclo tal para que toda la experiencia de la práctica y, al mismo tiempo, su lógica se transformaran ${ }^{48}$. Esas prácticas podían quedar interrumpidas por alguno de los protagonistas al incumplir la contrapartida del don y contradon, circunstancias que pudieron darse por motivos muy variados dado el carácter a largo plazo de los compromisos. Las dinámicas pudieron alterarse por razones externas a las reciprocidades establecidas -desde crisis demográficas hasta guerras y cambios bruscos en el poder- o internas, por ejemplo el estallido de tensiones grupales, comunitarias o individuales, dado que la continuidad en los encadenamientos establecidos no siempre era previsible ni controlable.

Con los acuerdos también se establecían formas nuevas de relación basadas en la proximidad. La comunidad campesina, hasta entonces sometida de manera laxa y alejada a la autoridad política - condes y reyes generalmente ausentes y representados por funcionarios que ejercían de manera irregular sus representaciones - se vio condicionada a partir de los acuerdos a cumplir los compromisos con un señor ahora más cercano y que además estaba organizado, dado que contaba con los gestores de sus granjas para controlar de manera más efectiva el cumplimiento de tales compromisos.

La heterogeneidad de los pactos entre Oseira y las comunidades campesinas nos obliga, a la hora de evaluar el equilibrio o la desigualdad en los acuerdos, a adentrarnos en un análisis prolijo de los mismos. En su desarrollo, algunos conceptos y elaboraciones de historiadores y antropólogos nos han proporcionado pistas valiosas a la hora de ponderar la relación de reciprocidad sin presuponer que estas prácticas de intercambio puedan ser analizadas como sistemas totales. En este sentido, consideramos, por una parte, que la reciprocidad era sólo un aspecto superficial del intercambio que cubría poderosas estrategias mucho más políticas, en especial las de "guardar mientras se da» ${ }^{49} y$, por otra, en la

47 Estudiados variados aspectos de esta problemática por Reyna Pastor en PASTOR, R., ALFONso ANTón, I., ROdRÍGuez LóPez, A. y SÁNCHez LeÓN, P.: Poder monástico y grupos domésticos en la Galicia foral(siglos XIH $-X V)$, especialmente pp. 99 en adelante.

48 Observación de Bourdieu, P.: El sentido práctico. Madrid, 1991, pp. 168 y 169, glosa.

49 Así lo dice para el intercambio en las sociedades «primitivas", criticando a Mauss: WEINER, A.: Inalienable Possessions.The Paradox of Keeping wbile Giving. Consideramos esta reflexión absolutamente trasladable al mundo feudal en sus comienzos que ahora tratamos de analizar. 
línea de trabajos recientes, que las construcciones de reciprocidad estaban básicamente sugeridas desde arriba, iniciadas por los señores aunque parecieran proceder de los campesinos ${ }^{50}$. La reciprocidad se entiende, así, no como una norma fundadora sino como una construcción, potencialmente conflictiva, disputada dentro de los campos de poder ${ }^{51}$, ante la cual la aceptación por parte de las comunidades campesinas estaba sujeta a diversas circunstancias.

De hecho, los casos históricos conocidos para la zona norte de la Península Ibérica, incluida la que ahora nos sirve de reflexión, muestran que los campesinos trataron muchas veces de rechazar los servicios a los señores y que, generalmente, fracasaron ${ }^{52}$. Influyeron en la configuración de los pactos de reciprocidad el desconocimiento colectivo de los campesinos sobre realidades ajenas a su entorno y el manejo político que podían ejercer los señores, lo que llevó a aceptar a las comunidades - plenamente o con reparos, mediante justificaciones religiosas, ideológicas y económico-sociales-, esas reciprocidades disfrazadas o ficticias que generaban un acercamiento entre ambos grupos sociales difícil de apreciar por su carácter alienado ${ }^{53}$.

\section{Antecedentes de la ficción.}

La base fundadora de la ficción de la reciprocidad se encuentra en una historia previa al momento de los acuerdos que se remonta a unos decenios atrás, cuando las comunidades y/o los grupos domésticos poseían o gozaban de un relativo acceso directo a la propiedad o a la posesión de la tierra. La implanta-

so En la documentación de Oseira a la que nos referimos son siempre las comunidades -por lo general parte de sus miembros los que encabezan los acuerdos, nombrados con nombre y apellidolos primeros protagonistas nombrados, los que primero dan (o se comprometen a dar); en segundo término el monasterio pacta su contradon, lo que equivale a decir que expresa sus condiciones.

"I Ver, en este sentido, ALGAZl, G.: «Feigned Reciprocity: Lords, Peasants, and the Afterlife of Medieval Social Strategies", en Negotiating the Giff..

32 Ver, entre otros, los estudios de PASTOR, R: Resistencias y luchas campesinas en la época del crecimiento y consolidación de la formación feudal. Castilla y León, siglos X-XIll. Madrid, 1980; también, "Revueltas campesinas en Castilla y León, siglos XI-XIII* en Revoltes populares contro el poder de IEstat, Barcelona, 1992, pp. 30-36: «Es manifiesto que los dominados tuvieron una conciencia bastante clara de las formas concretas por las que se ejercía sobre ellos el poder....Esta exigencia los llevó a consentir ante la fuetza, pero, tarnbién, a resistir y a rebelarse. $Y$ me parece que fue asi porque el poder feudal en la sociedad feudal aparece más dificil de legitimar que en otras sociedades, dado que la idea de reciprocidad estuvo sostenida por elementos muy débiles" (pp. 35-36).

\$3 BouRdieu, P.: El sentido práctico, pág 178, expresa esta idea: $\alpha_{. . .}$el funcionamiento del intercambio de dones implica un no-roconocimiento (méconnaissance) individual y colectivo de la verdad del «mecanismo» del objetivo del intercambio, aquella que la restitución inmediata desvela brutalmente, y del trabajo individual y colectivo necesario para asegurarlo: el intervalo de tiempo que separa el don del contradon es lo que permite concebir como irreversible una celación de intercambio que corre siempre el riesgo de aparecer y aparecerse como reversible, es decir, como obligada e interesada a la vez". 
ción formal del monasterio como señorío partía del hecho de haber recibido la posesión del coto y su jurisdicción desde la cúpula del poder, en este caso de los reyes. A partir de entonces, los nuevos señores comenzaron a comprar sistemáticamente sus tierras (o a recibirlas en donaciones) a los antiguos beredes, lo que provocó un proceso de transformación del sentido de la propiedad de la tierra y de la ubicación social de los campesinos. A los campesinos, comunidades y grupos domésticos, les fueron reentregadas las tierras por pactos, acuerdos o contratos. Desde ese momento, por las circunstancias conjuntas que llevaron a la transformación de la propiedad de la tierra, ahora feudal, quedaron sujetos a una ficción: la de que -exagerando y simplificando los términos- recibían como dones las tierras de las que, por diversos caminos, habían sido despojados. De allí las tensiones sociales y, en el polo opuesto, las aceptaciones por razones religioso-morales.

Se puede ampliar la explicación. Los campesinos que hemos estudiado fueron en principio mayoritariamente beredes, descendientes de antiguos propietarios cuyas tierras se habían subdividido mediante un sistema paritario y cognaticio de tal manera que se había ido debilitado su autonomía en todos los aspectos. Estos beredes tuvieron que aceptar el lazo señorial ${ }^{54}$, su dominación, porque - como acabamos de explicar- el primer acto de la relación feudal consistió en recibir el don de la posesión de la tierra, generalmente su propia beredad, que había pasado a ser propiedad señorial y jurisdiccional del monasterio. ${ }^{55}$ Fuera o no una ficción socioeconómica, los campesinos quedaban deudo-

5i En realidad estaban abocados a ello no sólo por las circunstancias concretas a las que hacemos referencia sino también porque la aceptación de una tierra o su recuperación era su única (o casi única) opción en la que jugaban no sólo la posesión condicionada de su medio de subsistencia sino mucho más que eso, significaba la proyección de su ser en el mundo exterior, dado que, como es sabido, la tierra no era para el campesino un objeto exterior, era para él una chalidad personal. Ya señaló Marx que la tierra no representaba en la sociedad feudal una materia muerta que dorninaba a los hombres: los hombres estaban como soldados a la tierra, tenían con ella una relación personal, una unión matrimonial respetable con ella». Ver GurEvic, A. Art. cit. También Marx resaltó, en otro momento la existencia de una poetización de la tierra (Boden-Poesie) propia del feudalismo romanogermánico. En términos similares, MARX, K.: Manuscritos de economía y fllosofía, Primer manuscrito, tradución, introducción y notas por RuBlo LloRenTE, F.: Madrid, 1968.

55 Existían distintos grupos sociales de carnpeșinos que hemos separado a efectos de análisis: Los beredes propietarios en primer término, a los que ahora nos referimos. Los que quedaron dentro del coto monástico son los que proporcionan las bases para el estudio de sus comunidades y del conjunto, dado que algunas de sus formas de relación persistirán en el proceso de feudalización y otra sufrirán transformaciones que llevaron lentamente al predominio de su participación «individualizadan, como pequeños posesores, los foreros, que funcionaban en forma más autárquica con relación a la comunidad y más ligada directamente al señor. Los pequeños propietarios que permenecen en las zonas del coto tienden a desaparecer sin hacerlo totalmente, se consolidan como parte de grupos «intermedios" que fueron formando una baja nobleza (analizada en la primeta parte del artículo) o simplemente se mantienen como "grupos intermedios inferiores", en ambos casos privilegiados - de muy distinta manera - por el poder monacal. Esta sociedad rural concaba también, en su grado más bajo, con una mano de obra escrictamente servil - posiblemente abundante en 
res de este primer y fundamental don, que les obligaba, de allí en adelante, a cumplir variadas formas de servicio y a prestaciones diversas, que posiblemente nunca consideraron totalmente compensadas por la entrega de sus contradones. ${ }^{56}$

\section{Los pactos de Oseira y las comunidades}

Las comunidades campesinas que aparecen en el cartulario de Oseira eran, como rasgo generalizado, muy locales. Se trataba de conjuntos poco densos y bastante dispersos, de organizaciones poco formalizadas con respecto al poder superior pero muy comprometidas en su interior, de tal manera que sus miembros - y por lo general sus descendientes - quedaban atados a ellas de por vida ${ }^{57}$. La organización campesina, por liviana que fuese, aparecía como un poder interno que obligaba a sus miembros a la cooperación mutua. Su cohesión fue siempre evidente, a pesar de que en su interior estaban diferenciados personas o grupos por sus distintos niveles económicos y/o por ocupar destacadas funciones «políticas» de representación y a pesar también de las presiones de sus vecinos, que podían ser personas privilegiadas con distintos estatus, como caballeros, escuderos.

\footnotetext{
términos relativos - documentada para los siglos X y XI, cuyo estatus ha sido estudiado para algunos monasterios aunque poco se conoce de ella. No la tratamos ahora por no tener datos suficientes para Oseira y por no entrar en el sistema que nos ocupa. Pero debe tenerse presente que en toda la sociedad gallega, en el siglo XIII, al menos, la movilidad social de algunos grupos fue considerable. Ver Transaccioner sin mercado...

s6 Seguimos las ideas de GODELIER, Maurice que han sido especialmente clarificadoras para nuestro estudio. Ver El enigma del don, especialmente p. 25. Ver nota 20.

57 Las comunidades carnpesinas se organizan de varias maneras, especialmente en el concejo nural, principal organización de la solidaridad campesina, tanto para la cooperación «interna» relacionada fundamentalmente con las necesidades de la producción agraria, como para la cooperación ampliada entre distintas comunidades próximas y asociadas - generalmente también jerarquizadas-o para cumplir cargas impuestas por los señores, como las sernas, las castelarias, etc. Los testimonios relativos a la realización de trabajos colectivos son frecuentes: canales de riego, molinos, azeñas, pesquecas, etc, demarcaciones de lindes el trazado de sendas y calzadas, otros muy complejos referidos a la demarcación de los pagos de viñas, su ampliación y su régimen de cultivos y vendimia. La necesidad de realizar conjuntamente la tarea de los cultivos cerealeros y sus trabajos, así como el aprovechamiento de las barbechadas por los animales, exigían acuerdos del conjunto de los moradores, así como las prestaciones especiales para la vigilancia del ganado, en las fronteras de los pagos y en las barbechadas, $y$ en los prados acotados separados, por ejemplo los linares. Para estos trabajos se designaba a hombres de la comunidad, quizá rotativamente, quiza por suertes, o por otras situaciones especiales. Otro imporranre aspecto de la cooperación era el del uso de bueyes para arar. Podían poseer las yuntas varios campesinos en conjuño o algunos más ticos que podían beneficiarse al facilitar a los otros sus yuntas. También era necesario organizar la explotación de los comunales, establecer el régimen de partición de leña y otros productos y, sobre codo, el de las pastura de los ganados, que exigían vigilancia de pastores y otros controles. Todo esto funcionaba sobre la base de una organización de conjunto. Hasta el siglo XII o el XIII las decisiones tuvieron caracter frecuentemente asambleario.
} 
Las comunidades en conjunto tenían limitación jurídica y social y un campo de acción también limitado y su historia se desarrolló en un marco jurídico de mutuas responsabilidades institucionales y políticas. Eran interdependientes ante el mercado, todos sus miembros respondían, en principio, por las deudas de todos y estaban organizadas en un asamblearismo participativo, si bien en el caso de Oseira no llegaron a formar concejos además del de la villa de Ribadavia. Fueron protagonistas de diversos actos jurídicos - pactos, donaciones, ventas, querellas, pesquisas, apelaciones, convenios, contiendas, foros, etc- en los que estaban presentes las normas preestablecidas, el peso de las actitudes prescriptivas.

Se presentan a continuación dos ejemplos en los que se pueden apreciar las posturas y los intereses de comunidades y señores. Ambos casos revelan aspectos distintos entre sí de las formas mediante las cuales se traban relaciones en la sociedad feudal, reciprocidades desiguales en las que las comunidades aparecen actuando con una cierta fuerza que, sin embargo, no logra ocultar su creciente debilidad ante las necesarias transformaciones que las nuevas circunstancias del poder les imponían.

En 1213 los hombres de Torrezuela — son nombrados 19, entre ellos una mujer- establecieron un convenio por el que dieron a Oseira la cantidad de 150 sueldos in aiutorium pro cautandam villa torozela, es decir, para los gastos que suponía el establecimiento de oficiales del monasterio, a cambio de pertenecer al coto de la villa. Puede calcularse que pagaron una cantidad que excedía los siete sueldos por cabeza de familia, suma ciertamente apreciable en la época y que podía equivaler al precio de una heredad pequeña. Los 19 hombres prometieron ser vasallos sólo del monasterio y servir a los monjes. Tenían que llevar a la granja de Mamoa Verde los frutos y los granos que debían entregar a Oseira. El monasterio no debía exigirles voces (trabajos en las granjas) que no hubieran sido convenidas. Darían luctuosa según lo hacían al tey y también gayosa. A cambio de lo que habían pagado, los hombres de Torrezuela pidieron a los monjes que les protegieran con su amor, facient nobis amorem. Además de esta protección, el monasterio debía cumplir fundamentalmente dos condiciones como acto de reciprocidad: la primera de ellas, que si los habitantes de la villa no estuvieran de acuerdo con el merino nombrado por el abad, podrían destituirlo; la segunda, derivada del hecho de pertenecer ahora al coto de Oseira, de ser sus hombres, que quedarían amparados por estar dentro de la jurisdicción monástica si hirieran o golpearan - en su defensa y en la de sus bienes- a personas que vinieran de fuera para hacerles daño: non imputabitur nobis pro voce et defendent nos sicut suos homines. Las condiciones económicas del pacto quedaban muy imprecisas. Por el contrario las jurisdiccionales se concretaban lo suficiente como para corroborar que éstas eran la finalidad del acuerdo.

La reciprocidad expresada en el amor y la protección debida por el monasterio hace muy patente el interés que tenía la comunidad de ser protegida de los ataques exteriores. Por el contexto de la documentación de Oseira, no cabe duda que los de fuera eran gentes de la baja nobleza, milites por entonces nume- 
rosos en la zona que por sus intenciones expansivas convenía mantener alejados tanto de los hombres de Torrezuela como del monasterio. Pero éste no es el único aspecto reseñable. La situación que revela el documento es de gran interés, ya que estos miembros de la comunidad campesina pagaton por formar parte del coto monástico, por pertenecer a una jurisdicción que acababa de configurarse sólo dos años antes, cuando el propio cenobio había comprado al rey Alfonso IX todo su coto. Sin embargo, los de Torrezuela tenían gran interés en ser vasallos de este señor y de ningún otro, según declaraban y, al mismo tiempo, lograron reunir los 150 sueldos necesarios para sellar el pacto y ayudar con ellos al monasterio. Con esta acción la comunidad demostraba estar en condiciones ventajosas para hacer el convenio, partía de una posición de cierta fuerza y podía pedir reciprocidad.

Ésta se expresa en cuatro formas diferentes: deben recibir el amor del monasterio (hecho espiritual pero también concreto, reflejado en la protección); los hombres podrán rechazar al maiorino si no es de su agrado (pueden en conjunto manifestar su oposición a un funcionario señorial); no se les impondrán otras cargas económicas ni de trabajo, ni se modificarán las eventuales como la luctuosa y la gayosa (condiciones sobre su trabajo y las cargas por sus cambios familiares) ${ }^{58} y$, finalmente, podrán defenderse con toda fuerza de quienes los ataquen con la seguridad de que no serán penados por ello. En esta última facultad del convenio pueden encontrarse formas de la ya por entonces antigua responsabilidad colectiva de las comunidades ante los homicidios y lesiones que podían infringirse a quienes entraran sin permiso en sus posesiones, que se seguirán practicando desde entonces bajo el amparo del monasterio. Esta nueva forma de defensa colectiva de la comunidad invita a recordar lo antes mencionado sobre persistencias de normas - consuetudinarias- prescriptivas y su transformación y parcial perduración ante nuevas circunstancias.

Veamos el otro documento. En 1207 se acuerda un pacto entre el abad de Oseira y los hombres de otro lugar - Aguada - sobre los servicios anuales que colectivamente tenían que prestar por ser vasallos monásticos y no de realen$\mathrm{go}^{59}$. El testimonio es especialmente interesante pues deja ver, entre otras cosas, a la comunidad campesina comprometida de manera colectiva en el pago de algunas cargas y servicios. Encabezan el pactum in perpetum con el abad y el convento 15 hombres con sus nombres y apellidos y lo suscriben pro filitis et nepotibus nostris et etiam pro omnibus bis qui bereditatem babent vel babuerint in predicta villa de Aquata, es decir, aparecen por ellos y como representantes de los demás, incluidos sus descendientes. Posiblemente estos representantes eran -

\footnotetext{
ss Vuelven aquí a aparecer las resistencias que los campesinos tenian para cumplir tanto los trabajos directos realizados para el señor, las sernas o corveas, como para pagar por los cambios familiares: casamientos, muertes, etc, como su secular rechazo por los merinos y arrendadores. Se han estudiado en PASTOR, R: Resistencias y luchas campesinas... pp. 213+245.

39 Documento ${ }^{\circ}$ I 19, Vol. I, pp. 129-130 
además de cabezas de familias- hombres destacados entre los vecinos, mayores en el sentido de importantes.

Anualmente debían entregar, en conjunto, 150 panes buenos y cada uno de los que moraban en la villa una olla llena de mijo, unas escudillas de lagamis o higos, un cabrito o dos gallinas. Todos estaban obligados a acudir a la cosecha en las granjas próximas al monasterio, hacer servicios de segar y mallar y tres veces al año a realizar las sernas con sus bueyes - lo que indica la diferencia social interna más elemental entre los campesinos que tienen y los que no tienen animales grandes-, sernas que también podían cumplir cerca de la villa según dispusiera el monasterio. Los que tuvieran cabalgaduras debían prestarlas una vez al año para ir a Santiago o a Marín y cuando el rey viniera al Oseira debían entregar cabritos y gallinas, testimonio de que se conservaba indirectamente el yantar regio. No podían dar amaticum ni criar a hijos de milites o domi$n i$. No debían tener otro señor ni poblar un lugar cercano en el caso de que tuvieran heredades en las proximidades del monasterio, referencia que revela la existencia de antiguos beredes que todavía podían conservar y explotar algunas heredades próximas al monasterio, ya que el sentido de poblar alude especialmente a tener animales en ellas. Los hombres de Aguada especificaban además que aceptaban el pacto porque el monasterio había comprado la villa y la había redimido de la potestad del rey y del dominus Gómez Pérez. Aquí queda patente que -mediante cambios de jurisdicciones o compras del monasterio al rey 0 a otros poderosos- se estaba llevando a cabo un proceso de despojo feudal de la tierra que también se ha rastreado en la realidad que ponía de manifiesto el documento de Torrezuela.

Por su parte, estos beredes, nuevos vasallos del monasterio, consiguieron en signo de reciprocidad que los monjes nunca les impusieran como mayordomo a un sarraceno o a un siervo monástico para no sentirse así injuriados (sec talis non faciat nobis iniuriam nec tortum). Ese deseo de de no estar sujetos a mayordomos sarracenos o a serviciales y las referencias a la injuria y al engaño posiblemente se relacionaban con experiencias negativas que se remontaban a la época en que se encontraban bajo jurisdicción regia o a un deseo de no ser controlados por personas no libres, es decir por gentes de condición sociojurídica inferior a la suya. En tal caso, esta es la única reciprocidad específica con la que el monasterio les retribuye. Son conocidos los otros posibles beneficios, como la inmunidad ante los oficiales del rey, o la exacción de deberes de fiscalidad y de cargas públicas $^{60}$.

60 PORTELA, E.: argumenta que los habitantes de los cotos monacales se veían privilegiados por la inmunidad otorgada a éstos por el rey, desde la entrada de los oficiales reales para administrar justicia hasta la exacción de deberes fiscales, de los servicios y de las cargas públicas. La colonización cisterciense en Galicia (1142-1250), Sanciago de Compostela, 1981, p. 124. En la nota 242 de la misma página cita un explícito documento de Alfonso IX en el que acota al Monasterio de Meira y dice: .et probibo ut nemini deinceps liceat intra cautos at divisiones memoratas violenter intrare, nec bomines ibi morantes pro petito, fossadayra seu foro alio quolibet impetere aut pignorare, nisi tantummodo pro moneta. 
El contenido de este documento es revelador del funcionamiento de la comunidad con respecto al nuevo señor. Una parte de las cargas impuestas seguramente existían ya cuando los hombres de Aguada pertenecían al realengo, pero parece evidente que las sernas eran ahora más fuertes y que estaban mejor organizadas y controladas aunque no fuera más que por la proximidad del monasterio. Por otra parte, el hecho de que tuvieran que aportar los animales para el trabajo en las sernas exigía una cooperación interna de la comunidad. El pacto muestra en detalle los compromisos de renta y trabajo con el monasterio, pero además deja entrever los problemas que podía ocasionar el paso del coto regio al monacal y otros de carácter ideológico expresados por los hombres de Aguada. Pero, a pesar de la dificultad para evaluar el acuerdo, salta a la vista el desequilibrio que se establece entre las partes.

En los pactos presentados - y en los restantes estudiados ${ }^{61}$ - se aprecia que había varios tipos de comunidades y de acuerdos en los que se conformaba una multiplicidad de reciprocidades. De hecho, no puede aislarse ningún factor microautónomo, ni desde el punto de vista económico ni desde el social, sino que la explicación de las unidades campesinas debe ser de conjunto, a través de los nexos que las vinculaban. La lógica de la reciprocidad y la de la redistribución del excedente formaban ambas parte de la base de la identidad colectiva e individual. Filósofos, antropólogos y economistas - desde Marx a Mauss, Polanyi o Evans-Pritchard- describieron las acciones de las comunidades campesinas como dirigidas al mantenimiento del posesor y del cuerpo comunitario en su totalidad. Para todos ellos, la emergencia del impulso individual hacia la subsistencia es el resultado contingente de la acción de la identidad dentro del cual el propósito colectivo de subsistencia prevalece. Este proceso, como ha señalado Brenner, explicaría para muchos la irracionalidad de los campesinos en las crisis. Para comprender estos supuestos se hace necesario, por ello, conocer el vínculo entre las estructuras y la acción individual ${ }^{62}$.

(publicado por GoNZÁLEZ, J.: Alfonso IX, vol. II, p. 565). Romaní, M.: en su estudio histórico sobre Oseira matiza esta afirmación, pues dice que «en la jurisdicción acotada del monasterio las cargas resultarían no precisamente más benéficas, pero si menos abultadas y quizá más negociablesm.(p. 99). Añade que también habría un segundo motivo que es la presión que, de alguna manera, ejercía el cenobio.

61 Transacciones sin mercado... pp. 198-232.

62 Por su parte Chayanov (y Adam Smith) cuando estudian las unidades campesinas destacan más a las organizaciónes de los campesinos en sus distintos grupos familiares que a las comunidades, y afirman que, para éstas unidades, la morivación más importance era la aversión al siesgo y la necesidad de seguridad. Resaltan, por tanto la autonomía de la familia campesina, establecida en cierras bien en posesión bien en propiedad, y su funcionamiento prácticamente autárquico, con fuerte predominancia del autoabastecimiento y poca relación con el mercado. Aversión al riesgo, necesidad de seguridad y relaciones internas de la familia campesina (de cualquier tipo, nuclear o extensa) señalan un comportamiento individualista y utilitario de esos pequeños grupos. Las dos posiciones a las que hacemos referencia tienen su adeptos y surgen sobre todo de la observación empírica y 
Las reciprocidades entre grupos alejados socialmente. El monasterio y los grupos domésticos foreros.

\section{La centralidad de la organización familiar.}

Unas reflexiones finales sobre la organización de los grupos domésticos y de la familia son imprescindibles para comprender su doble funcionamiento en las reciprocidades horizontales y en las verticales.

Las unidades de explotación en Oseira se componían prioritariamente de heredades individualizadas, en las que las tierras de agricultura eran fundamentales mientras que las de explotación comunitaria ocupaban por lo general un espacio económico menos importante. En esta zona de Galicia, el hecho de que la ganadería fuera escasa -estabulada o de corral en su mayoría - y no necesitara trashumancia, constituía un rasgo diferenciador que acentuaba la individualidad de las explotaciones familiares. Disminuían por ello importantes aspectos de la acción colectiva relacionados con la explotación ganadera y la trashumancia tan presentes, por ejemplo, en Castilla.

Aun teniendo en cuenta esta carencia, las relaciones internas de solidaridad y de cooperación de los grupos domésticos entre ellos y con sus parientes y vecinos explican las formas de las solidaridades y cooperaciones que se extendían a la totalidad de la comunidad, mostrando así el funcionamiento de una parte sustancial de sus bases relacionales. Desvelan el núcleo quizá más importante de la convivencia y de la organización campesinas. En el interior de las familias funcionaban reglas morales, que las dejaban sometidas a variadas obligaciones que conocemos en buena parte. El peso del parentesco, además de estar sometido a normas que ordenaban las relaciones familiares y las alianzas, regulaba también otros aspectos de la vida de las comunidades generalmente muy ligadas por emparentamientos cruzados ${ }^{63}$.

Los grupos domésticos — por lo general familias conyugales o troncalestenían en un principio una estructura cognaticia que implicaba el reparto igualitario de la herencia de la propiedad/posesión primero $\mathrm{y}$, más tarde, del foro o contrato enfitéutico individualizado. Las formas del reparto hereditario debilitaban la capacidad económica de las familias aunque éstas optaran frecuentemente, como defensa de sus intereses, por dejar la tierra indivisa. A su vez esta opción promovía la jerarquización interna del grupo familiar. Las semejanzas entre las unidades familiares que formaban estos conjuntos comunitarios pese a la relativa importancia de sus diferenciaciones internas- dieron lugar al

teórica de distintas realidades sociopolíticas desarrolladas en diferentes medios geográficos y en distintas épocas.

63 Personalizaban por ejemplo las transacciones de compras de tierras a las que los parientes estaban moralmente sometidos por una serie de obligaciones y dependencias. Así lo hernos demostrado en nuestros trabajos mencionados. También lo ha dernostrado RAZI, Z.: en «Family, land and the Village Community in Later Medieval England", Past and Present, 93 (1981), pp. 3-36. 
desarrollo de las relaciones de reciprocidad borizontal que se manifestaban como la forma de integración más destacada entre esas unidades ${ }^{64}$. Pero en el tránsito a la señorialización monacal se produjeron transformaciones, tanto en las alianzas familiares como en la explotación económica.

La documentación que conocemos se refiere mayoritariamente al momento en el que se traban las relaciones de producción por un bien de uso, la tierra, entre el señor y los arrendatarios o foreros, en las que están también presentes o implícitas las relaciones de alianza. Para obtener un foro en Galicia -así como para ser vecino, morador o solariego, en otros lados- hacía falta estar casado (vivir en pareja) o comprometerse a estarlo. De esta manera los contratos aseguraban al señor la ocupación efectiva del suelo, la renta y la reproducción a largo plazo de ella a través de la reproducción de la mano de obra in situ. Por tanto, los grupos domésticos organizaron internamente sus relaciones de otra manera dado que, por ejemplo - como estipulaba generalmente el forolos padres debían elegir en vida a un hijo o hija como titular del foro a su muerte. Se generaban entonces nuevas formas de jerarquías internas en el grupo doméstico así como rivalidades y conflictos ${ }^{65}$.

Se puede afirmar, por todo ello, que al crear una estructura productiva expresada en un contrato de trabajo y renta enfitéutico -el foro- que incluía condiciones relacionales de carácter vasallático/moral, se sentaban las bases para crear o consolidar y desarrollar una estructura de parentesco afín a la económica. Se constituía así la base doble y complementaria de la estructura de poder señotial que repercutía, al parecer indirectamente, en la estructura familiar de los receptores. En este sentido, el estudio de las sucesiones de parientes y de amigos cuando ya estaba plenamente vigente el sistema feudal/forero muestra las formas de la intromisión señorial en la organización interna familiar e indica además que, como señor, prefería conservar la mano de obra y la renta dejando una cierta libertad interna al grupo familiar ${ }^{56}$.

64 Como dice ValENSI, L.: en su artículo «Antropologie économique et Histoire: L'oeuvre de Karl Polany», Annates (E.S.C.), (1974), 6, pp. 1312-1313, "Uno de los principios de integración del proceso económico, el de la reciprocidad, se vió favorecido por el modelo institucional de simetría de la organización social. Asímismo el dualismo, recurrentemente observado en los grupos de parentesco....puede mostrar un cuadro adaptado a estos tipos de intercambios. La reciprocidad interviene en la producción (prestaciones de servicios, reparticiones periódicas de tierras (o de bosques y pasturas) como en la repartición de productos, por la práctica del don y del contradon, las distribuciones ceremoniales de alimentos.."

65 También había otras jerarquías entre los foreros: algunos, además de foros, conservaban una pequeña propiedad y podían actuar en dos esferas comunitarias y relacionales, lo que les daba mayores oportunidades de acción; también se formaron grupos de parientes que tenían adjudicados, por familias, uno o más foros y que podian cooperar entre ellos más eficazmente, organizando con mayores posibilidades de éxito sus alianzas parentelares. Estaban en su conjunto más próximos a los intereses del monasterio y a sus redes de influencia.

${ }^{66}$ Esta libertad interna consistía en permitir la elección del hijo o hija sucesor en la tirularidad del foro, aunque no hay que olvidar la influencia «indirecra» que podía ejercer el monasterio a través 
Las reciprocidades como marco y limite a la movilidad social y al desarrollo económico.

La extensión generalizada del sistema forero dio lugar al predominio de las explotaciones familiares dependientes directamente de señores en todos los sentidos: social, económica, política y espiritualmente. Por ser un sistema de relaciones individuales $\longrightarrow$ de subgrupos familiares - entre señores y campesinos representó un avance en la cohesión política de la clase de poder al mismo tiempo que el debilitamiento de los lazos comunitarios campesinos. La mayor parte de los foros tenían similares exigencias de renta, aunque no existió un modelo tipo que se aplicara mecánicamente. Los campesinos estaban obligados a cumplir sernas para las labores de los cereales y las viñas, se pagaban algunas monedas por el reconocimiento de la renta señorial, frecuentemente se exigía la luctuosa, se prohibía la crianza de los hijos de los milites o de los nobles y los foreros se comprometían a no tener otro señor más que Oseira ${ }^{67}$.

El foro era un contrato ambiguo en términos de derecho de propiedad y relaciones personales e incluía un hecho paradójico que ha destacado Esther Pascua: el forero podía enajenar la tierra a otro de igual estatus, podía venderla, es decir disponer de una tierra de cuya propiedad eminente no tenía, podía ponerle precio frente al supuesto propietario de la misma, el monasterio. Toda transacción de una tierra exigía "comprarla», es decir, establecer un vínculo entre personas y bienes redefiniendo los derechos de cada uno con respecto a la tierra y de una parte con respecto a la otra ${ }^{68}$.

En los casos gallegos estudiados parece confirmarse la existencia de una centralidad de la organización familiar/forera en todas sus formas: en su relación directa con la tierra, en su autoabastecimiento, en su organización familiar para el trabajo y la reproducción. Pero la relación feudal/foral, más que la comunitaria, impidió a las unidades familiares dar el paso hacia una autonomía económica y política. No pudieron, por ejemplo, salirse del marco rural ni crear actividades marginales que les permitieran una acumulación suficiente como para relacionarse directamente con un mercado urbano de manera que les facilitara un cambio en las relaciones de dependencia. Aunque se formaron categorías diversas de grupos sociales intermedios, no lo hicieron a partir de relaciones con el mercado.

La unidad económica estaba individualizada - aunque era parte de un conjunto con similitudes y nexos internos- lo mismo que el trabajo campesino, por lo que el propietario señorial tomaba como index para su apropiación no a

de las confesiones, de consejos dados a los padres, etc. Cabe pensar también que los monjes conocían por experiencia directa la fragilidad de los ciclos vitales de los campesinos y preferían dejar cierta movilidad en las elecciones a fin de no generar conflictos intrafamiliares inútiles.

67 Para ver los detalles de estos contratos, PASTOR, R: Transacciones sin mercado.., pp. 228-229.

\& PASCUa Echegaray, E.: en: "Vasallos y aliados con conflictos: las relaciones entre Santa María de Montederramo y la sociedad local gallega del siglo XIII". en Transacciones sin mercado.., pp. $39-40$.

Hispania, LX/1, núm. 204 (2000) 63-101 
colectivos amplios sino a unidades económicas concretas a cuya cabeza estaba una familia o un grupo doméstico ${ }^{69}$. El señor funcionaba como una entidad de individualización y ejercía por lo tanto sus derechos a partir de las posibilidades de apropiación cuantitativa y cualitativa que le permitía su poder dominical y jurisdiccional y establecía una gama compleja y disociada en la organización y distribución de ese poder.

Ante estas circunstancias el monasterio no intentó transformar substantivamente la renta, las superficies de las explotación ni los sistemas productivos. Ésto con dos excepciones: una, que extendió en algunas zonas el cultivo de la vid, tanto por medio de foreros individualizados o grupos, y otra, que otorgó contratos ad plantandum, que interpretamos como formas feudales de organizar comunidades. Estas actitudes evidencian una planificación política y económica simple llevada a cabo por el monasterio que consistía en traer a gentes próximas con vistas a extender los cultivos o a agrupar los viñedos, pero no a cambiar el sistema de relaciones de producción ni en el interior de las comunidades ni en las relaciones entre comunidades diferentes. Se repetían por lo tanto los lazos de reciprocidad y algunas formas de redistribución, así como las de parentesco, de vecindad. Pero en el proceso de señorialización se fueron transformando de tal manera los nexos de reciprocidad que, aunque persistiendo formalmente, se fueron reduciendo a una escueta devolución de servicios a los señores en renta y trabajo.

Es también muy posible que una parte de lo que el monasterio iba obteniendo de la producción - como el vino, por ejemplo- entrase en circuitos mercantiles más amplios, lo que le habría permitido obtener una cierta acumulación de moneda y realizar otro género de intercambios mercantiles. Pero es evidente que en esta época el monasterio, en su escala económica más amplia y aun contando con su participación en el mercado, centró su economía y su poder en la acumulación de bienes rurales de consumo, procedentes de sus relaciones de reciprocidad, que repartió, con mayor o menor intensidad según épocas e intereses, para establecer alianzas con otros señores y para pactar - como se ha visto-. con grupos sociales intermedios altos que él mismo promovió como forma de contar con su fidelidad. Por tanto, su posible participación en un mercado más complejo, por ejemplo, en Rivadavia o en Marín, no llegó a provocar un cambio cualitativo - -hacia formas más modernas que contaran con la participación de grupos mercantiles--en la economía y en la política del monasterio.

69 El desarrollo del sistema de foros en Oseira y su entorno se conscata desde el segundo decenio del siglo XIII. Lo fue imponiento el monasterio pero también fue practicado por la nobleza alta y baja y campesinos ricos con has mismas condiciones generales. Compartir el sistema en canto forma de relaciones sociales, económicas y políticas, indicaba que era considerado por los grandes y medianos propietarios feudales como más apto y operativo que la explotación directa de las tierras por siervos de distintos estatus.

Hispania, LX/1, núm. 204 (2000) 63-101 


\section{A MODO DE CONCLUSIÓN}

La sociedad local en el entorno de Oseira se encontraba ya jerarquizada antes de la constitución del poder monástico y de la organización de su dominio en las décadas centrales del siglo XII. Se diferenciaban grupos familiares que ejercían un cierto control de recursos económicos y políticos y comunidades campesinas, muy heterogéneas y con todos los matices en su caracterización que se han señalado en las páginas previas. Sobre este complejo mundo local se establecieron los cistercienses. Las situaciones previas condicionaron los modos de relación, pero a su vez esa relación transformó las jerarquías existentes. El poder monástico introdujo una cuña que definió nuevas posiciones, en un proceso dialéctico marcado por estrategias diversas en las que jugaban, entre otros, factores vinculados a las formas de propiedad y explotación de la tierra, a la continuidad o a la disgregación de los grupos de parentesco y a las necesidades de la gestión monástica. Se conformaron así múltiples compromisos en el curso de este proceso. Fueron generosidades necesarias pero, ante todo, fueron reciprocidades selectivas, dirigidas y desequilibradas. 